\title{
Relationships between Mitochondrial Dysfunction and Neurotransmission Failure in Alzheimer's Disease
}

\author{
Kan Yin Wong ${ }^{1}$, Jaydeep Roy ${ }^{1}$, Man Lung Fung ${ }^{1}$ Boon Chin Heng ${ }^{2}$, Chengfei Zhang ${ }^{3}$, Lee Wei \\ Lim $^{1 *}$ \\ ${ }^{1}$ School of Biomedical Sciences, Li Ka Shing Faculty of Medicine, The University of Hong Kong, Hong Kong, \\ China. \\ ${ }^{2}$ Peking University School of Stomatology, Beijing, China. \\ ${ }^{3}$ Endodontology, Faculty of Dentistry, The University of Hong Kong, Hong Kong, China.
}

[Received September 19, 2019; Revised November 16, 2019; Accepted November 25, 2019]

\begin{abstract}
Besides extracellular deposition of amyloid beta and formation of phosphorylated tau in the brains of patients with Alzheimer's disease (AD), the pathogenesis of $\mathrm{AD}$ is also thought to involve mitochondrial dysfunctions and altered neurotransmission systems. However, none of these components can describe the diverse cognitive, behavioural, and psychiatric symptoms of AD without the pathologies interacting with one another. The purpose of this review is to understand the relationships between mitochondrial and neurotransmission dysfunctions in terms of (1) how mitochondrial alterations affect cholinergic and monoaminergic systems via disruption of energy metabolism, oxidative stress, and apoptosis; and (2) how different neurotransmission systems drive mitochondrial dysfunction via increasing amyloid beta internalisation, oxidative stress, disruption of mitochondrial permeabilisation, and mitochondrial trafficking. All these interactions are separately discussed in terms of neurotransmission systems. The association of mitochondrial dysfunctions with alterations in dopamine, norepinephrine, and histamine is the prospective goal in this research field. By unfolding the complex interactions surrounding mitochondrial dysfunction in $\mathrm{AD}$, we can better develop potential treatments to delay, prevent, or cure this devastating disease.
\end{abstract}

Key words: Alzheimer's disease, mitochondrial dysfunction, monoaminergic, neurotransmission dysfunction

\section{Introduction}

Alzheimer's disease (AD) is characterised by progressive cognitive deterioration that manifests with behavioural and psychiatric symptoms [1]. Alzheimer's disease accounts for $60 \%$ to $80 \%$ of all dementias [2] and is estimated to affect 115.4 million people worldwide by 2050 [3]. The increasing prevalence of $\mathrm{AD}$ and the extreme burdens on individuals and society have led to extensive research into this devastating disease. Despite great efforts over the past few centuries, its molecular origin remains obscure and no treatments can delay or prevent this disease. Since the development of the amyloid cascade hypothesis in the early 1990s, deposition of amyloid plaques in the brain following amyloidosis is considered as one of the leading hypotheses [4]. Some patients with $\mathrm{AD}$ have autosomal dominant inherited mutations on amyloid precursor protein (APP), presenilin 1 and 2 genes [5, 6]. In particular, the mutations on presenilin 1 and 2 genes induce subsequent mutations on $\gamma$ secretase $[5,6]$. These eventually lead to defective APP processing, forming $A \beta$ proteins consisting of 42 amino acids [5]. These faulty $A \beta$ proteins are prone to accumulation and account for the plaque deposition

*Correspondence should be addressed to: Dr. Lee Wei Lim, School of Biomedical Sciences, Li Ka Shing Faculty of Medicine, The University of Hong Kong, Hong Kong SAR, China. Email: drlimleewei@ gmail.com

Copyright: ( 2019 Wong KY et al. This is an open-access article distributed under the terms of the Creative Commons Attribution License, which permits unrestricted use, distribution, and reproduction in any medium, provided the original author and source are credited. 
leading to neurodegeneration in early-onset familial AD. Interestingly, this familial type only appears in a minority $(1 \%-5 \%)$ of the AD population [7].

The majority (more than 95\%) of the AD population have the late-onset sporadic type [7]. The welldocumented pathological hallmarks of sporadic $\mathrm{AD}$ include deposition of $\mathrm{A} \beta$ plaques and neurofibrillary tangles of phosphorylated tau (P-tau) $[5,8,9]$. Although the root cause for sporadic $\mathrm{AD}$ remains unknown, the most investigated risk factor is apolipoprotein E4 gene, which leads to increased $A \beta$ production and plaque formation $[7,10,11]$. However, the above risk factor and pathological hallmarks are not always found in patients with the sporadic type [7], implying the existence of other causes of AD. Subsequently, a mitochondrial cascade hypothesis was proposed $[12,13]$, in which mitochondrial dysfunction is a driving force leading to $A \beta$ plaque deposition in $\mathrm{AD}$. In fact, mitochondrial damage was identified as one of the early events in AD pathogenesis $[14,15]$ and was strongly associated with age-related factors such as non-specific mitochondrial DNA (mtDNA) damage, reactive oxygen species (ROS), and Ptau [16]. Recently, the mitochondrial cascade hypothesis was refined into primary and secondary mitochondrial cascades [17]. The primary cascade is similar to the original hypothesis that mitochondrial dysfunction induces pathological hallmarks such as $\mathrm{A} \beta$ and P-tau [13, 17], whereas the secondary cascade posits that mitochondrial dysfunction is an intermediate step majorly initiated by $\mathrm{A} \beta$ deposition [17].

Considering the excellent reviews on the associations of $\mathrm{A} \beta$ and P-tau with mitochondrial dysfunctions in [1719], we will only briefly describe their interactions on the role of mitochondrial dysfunction in $\mathrm{AD}$. Both $\mathrm{A} \beta$ and $\mathrm{P}$ tau interfere with the electron transport chain, which affects energy production [20,21], as well as induces mitophagy, leading to excessive loss of mitochondria [22, 23]. Specifically, $A \beta$ causes mitochondrial dysfunctions by arresting transmembrane translocase on mitochondria, interacts with cyclophilin D to hinder the bioenergetics, and facilitates the opening of mitochondrial permeability transitional pores (mPTP) [21, 24]. In addition, $A \beta$ is associated with altered gene expressions that increase mitochondrial fission [21], and amyloid-binding alcohol dehydrogenase contributes to oxidative stress in mitochondria [21, 25]. As for P-tau, it increases dynaminrelated protein 1 level, which leads to enhanced GTPase enzymatic activity and excessive mitochondrial fragmentation [26].

Another pathological change in $\mathrm{AD}$ patients is the disruption of neurotransmission, which can be observed in the early phases of $\mathrm{AD}[27,28]$ leading to clinical manifestations. Cholinergic and monoaminergic systems have been reported to be altered in AD brains [29]. In particular, the cholinergic system, which regulates memory function and behaviour via the release of the neurotransmitter acetylcholine (ACh) [30], was found to be altered in $\mathrm{AD}$ in the 1980s. Accumulation of intraneuronal $\mathrm{A} \beta$ in $\mathrm{AD}$ degenerates basal forebrain cholinergic neurones and reduces ACh levels [31], which in turn leads to memory deficits [32]. Moreover, monoaminergic systems have also been reported to be defective in AD. Monoaminergic system involve various neurones in the brain that control neurocognitive and neuropsychiatry functions through regulating the release of serotonin (5-HT), dopamine (DA), norepinephrine (NE), and histamine (HA) [33]. Several reports have indicated a significant reduction of 5-HT [34], DA [35] and NE [36] levels as well as their receptors in AD brain, leading to neuropsychiatric and neurocognitive deficits [37]. In $\mathrm{AD}$, loss of 5-HT results in depression, anxiety and agitation [38], whereas dysregulation of DA release leads to reward-mediated memory formation deficits [39], and low level of NE impairs spatial memory function [40]. Unlike the other monoaminergic neurotransmitters, HA showed altered levels in different AD cases [33], which not only leads to changes in learning behaviour, but also neuroinflammation contributing to disease progression [41].

It is very clear that mitochondria and neurotransmission dysfunctions are involved in $\mathrm{AD}$ and play an important role in its pathogenesis and clinical symptoms. Understanding the interactions between mitochondrial and neurotransmission dysfunctions are crucial to elucidating the specific mechanisms contributing to the clinical symptoms in AD. Although the associations between mitochondrial dysfunctions and general synaptic deficits were recently reviewed in [18, 42-45], specific interrelationships between mitochondrial dysfunctions and failure in neurotransmission systems is still missing. Therefore, this review aims to examine how mitochondrial dysfunctions affect neurotransmission contributing to $\mathrm{AD}$ symptoms, and vice versa, how neurotransmission disruptions, such as in cholinergic and monoaminergic systems, cause mitochondrial dysfunctions.

\section{Outline of the review}

In this review, we first provide a description of mitochondrial dysfunctions in $\mathrm{AD}$, and then discuss the relationships with neurotransmission deficits, how they can trigger one another, and their roles in disease pathogenesis. We identified peer-reviewed articles in the PubMed database and Google Scholar web search engine using the following search terms: 'Alzheimer"' AND ('mitochondria' OR 'oxidative stress') AND ('neurotransmission dysfunction' OR 'acetylcholine' OR 
'monoamine' $O R$ 'serotonin' $O R$ 'dopamine' $O R$ 'norepinephrine' OR 'noradrenaline' OR 'histamine'). Additional relevant articles were identified from the reference lists of the included articles, review papers, and book chapters. Only original data were incorporated in this review, whereas review papers were used to provide context and background information.

Table 1. Summary of specific types of mitochondrial dysfunctions in Alzheimer's disease.

\begin{tabular}{|c|c|c|}
\hline \multirow{2}{*}{$\begin{array}{l}\text { Mitochondrial dysfunctions } \\
\text { Bioenergetic failure } \\
\end{array}$} & \multicolumn{2}{|r|}{ References } \\
\hline & & \\
\hline \multirow{4}{*}{ TCA cycle impairment } & Pyruvate dehydrogenase complex $\downarrow$ & {$[54,55,58]$} \\
\hline & Transketolase $\downarrow$ & {$[55]$} \\
\hline & Alpha-ketoglutarate dehydrogenase complex $\downarrow$ & {$[55-58]$} \\
\hline & $\begin{array}{l}\text { Isocitrate dehydrogenase } \downarrow \text {, } \\
\text { Succinate dehydrogenase } \uparrow \text {, and } \\
\text { Malate dehydrogenase } \uparrow\end{array}$ & {$[58]$} \\
\hline \multirow{5}{*}{ ETC impairment } & Complex IV $\downarrow$ & {$[20,59-61]$} \\
\hline & Haem-a (structural component of complex IV) $\downarrow$ & [62-64] \\
\hline & Transmembrane arrest of TOMM40 \& TIM 23 pores & {$[65-67]$} \\
\hline & Complex I $\downarrow$ due to phosphorylated tau & {$[20]$} \\
\hline & Complex V Dysregulation & {$[68,69]$} \\
\hline \multirow{5}{*}{ Oxidative stress } & Complex IV $\downarrow$ with complex III remains intact or $\uparrow$ & [71] \\
\hline & Oxidative scavengers (SOD, GPx \& GSH) $\downarrow$ & {$[72,73]$} \\
\hline & Reactive oxygen species level $\uparrow$ & {$[71,74-76]$} \\
\hline & $\uparrow$ Peroxidation of $A \beta$-bind alcohol dehydrogenase in $\mathrm{H}_{2} \mathrm{O}_{2}$ & {$[25,77,78]$} \\
\hline & Peroxidation by haem-A $\beta$ complexes $\uparrow$ & {$[79,80]$} \\
\hline \multicolumn{3}{|l|}{ mtDNA damage } \\
\hline Specific damage & mtDNA mutations at T477C, T146C \& T195C & {$[107]$} \\
\hline Non-specific damage & $\begin{array}{l}\text { mtDNA mutations stay at heteroplasmic state and accumulates until } \\
\text { energy production impairs }\end{array}$ & {$[111,112]$} \\
\hline \multirow[t]{2}{*}{$\mathrm{Ca}^{2+}$ dysregulation } & $\begin{array}{l}\mathrm{Ca}^{2+} \text { influx } \uparrow \text { from extracellular \& endoplasmic reticulum to } \\
\text { cytosol upon excitotoxicity }\end{array}$ & {$[92,113-115]$} \\
\hline & $\mathrm{Ca}^{2+}$ influx $\uparrow$ into mitochondria via mPTP & [116] \\
\hline \multirow{5}{*}{$\begin{array}{l}\text { Defective morphology and } \\
\text { dynamics }\end{array}$} & Fission $\uparrow$ with fusion $\downarrow$, possibly related to corresponding genes & {$[108,119-121]$} \\
\hline & Size changes (smaller, spherical, swollen, and/or elongated) & {$[118,120,121]$} \\
\hline & Mitochondrial transport to synaptic terminal $\downarrow$ & {$[125]$} \\
\hline & Cristae $\downarrow$ and paler matrix & [120]; Reviewed in [118] \\
\hline & Mitophagy $\uparrow$ due to phosphorylated tau & [22] \\
\hline Defective mitophagy & $\begin{array}{l}\text { PINK } 1 \downarrow \text { and parkin } \downarrow \text {, leading to autophagosomes } \downarrow \\
\text { and dysfunctional lysosomes } \uparrow\end{array}$ & $\begin{array}{l}{[130] ; \text { Reviewed in [22, }} \\
23]\end{array}$ \\
\hline \multirow{3}{*}{ Membrane permeabilisation } & mPTP opening $\uparrow$ with cyt $\mathrm{c}$ release & {$[131,132]$} \\
\hline & $\mathrm{A} \beta$ bind to VDAC $\uparrow$ leading to $\mathrm{mPTP}$ opening $\uparrow$ & {$[123]$} \\
\hline & $\begin{array}{l}\text { TrkA receptor on cell membrane } \downarrow \\
\text { Extracellular proNGF } \uparrow \\
\text { Results: pro-apoptotic signalling } \uparrow \text {, and mPTP opening } \uparrow\end{array}$ & {$[135-137]$} \\
\hline
\end{tabular}

The ' $\uparrow$ ' indicates increased level or being stimulated, while ' $\downarrow$ ' indicates decreased level or being inhibited. Abbreviations: $A \beta$, amyloid beta; $\mathrm{Ca}^{2+}$, calcium ions; cyt c, cytochrome c; GPx, glutathione peroxidase; GSH, reduced glutathione; $\mathrm{H}_{2} \mathrm{O}_{2}$, hydrogen peroxide; mPTP, mitochondrial permeability transition pore; mtDNA, mitochondrial deoxyribonucleic acid; NGF, neuronal growth factor; SOD, superoxide dismutase; TIM23, translocase of the inner membrane 23; TOM40, translocase of outer mitochondrial membrane 40 homolog; TrkA, tropomyosin receptor kinase A; VDAC, voltage-dependent anion channels.

\section{Mitochondrial dysfunctions in AD}

Mitochondria are rod-shaped double membrane intracellular organelles that are the powerhouse of cells.
Under aerobic conditions, they produce energy in the form of adenosine triphosphate (ATP) via the tricarboxylic acid (TCA) cycle and electron transport chain (ETC). The ETC oxidises nicotinamide adenine dinucleotide (NADH) and 
flavin adenine dinucleotide $\left(\mathrm{FADH}_{2}\right)$ from the TCA cycle using oxygen to generate water and ATP, known as oxidative phosphorylation (OXPHOS). In fact, considering $20 \%$ of the body's energy is consumed by the brain [46] and around 93\% of all cellular energy is produced by mitochondria [47], the mitochondrion is an indispensable energy source for the neuronal system. Besides providing energy, mitochondria are also involved in intracellular calcium $\left(\mathrm{Ca}^{2+}\right)$ regulation, cellular redox control, and programmed cell death/apoptosis. Many studies have reported that mitochondria appear to be defective in $\mathrm{AD}$. In this section, we review mitochondrial dysfunctions in $\mathrm{AD}$, including impaired cellular energy production, oxidative stress, mtDNA damage, $\mathrm{Ca}^{2+}$ dysregulation, impaired mitochondrial dynamics, and mitochondrial membrane permeabilisation (Table 1).

\subsection{Impaired energy production in mitochondria}

As early as the 1980 s, reduced glucose metabolism was reported in $\mathrm{AD}$ and mitochondrial dysfunction was considered to be a major contributor. Numerous lines of evidence have suggested that glucose metabolism is decreased in the frontal, parietal, temporal, and posterior cingulate cortices of $\mathrm{AD}$ patients, possibly due to a disturbed TCA cycle [48-53]. This bioenergetic failure was associated with lower levels of pyruvate dehydrogenase complex (PDHC) [54, 55], transketolase [55], and alpha-ketoglutarate dehydrogenase complex (KDGHC) [55-58], as well as alterations in other TCA cycle enzymes [58], hence, these enzymes are less active in $\mathrm{AD}$ leading to hindered energy production by mitochondria.

Furthermore, complexes I and IV (cytochrome oxidase, COX) in the ETC were found to be impaired in $\mathrm{AD}$. The reduced efficacy of COX is the most documented change in $\mathrm{AD}$ [20, 59-61], which is associated with (1) a deficiency in its structural complex haem-a [62-64]; (2) transmembrane arrest of translocase of the outer mitochondrial membrane $40 \mathrm{kDa}$ (TOMM40) and translocase of inner membrane subunit 23 (TIM23) protein pore related to A $\beta$ and APP processing [65-67]; and (3) mtDNA damage. Diminished activity of complex I was also reported in AD as a result of P-tau [20]. Besides, dysregulated complex V (also known as ATP synthase) was reported in human with $A \beta$ pathologies and tau transgenic (Tg) mice [68]. Interestingly, Beck et, al [69] emphasised a strong association between dysregulated complex $\mathrm{V}$ and loss of oligomycin sensitivity conferring protein (OSCP) and increased formation of mitochondrial permeability transition pores (mPTP) in $\mathrm{Tg}$ mice. The mPTP will be discussed in the upcoming section 3.6. Thus, it is reasonable to assume mitochondria are involved in bioenergetic failure in $\mathrm{AD}$.

\subsection{Oxidative stress induced by mitochondria}

Oxidative stress occurs when reactive oxygen species (ROS) accumulates in mitochondria and cytosol. Superoxide anion $\left(\mathrm{O}_{2}{ }^{-}\right)$, hydrogen peroxide $\left(\mathrm{H}_{2} \mathrm{O}_{2}\right)$, and hydroxyl radical $(\mathrm{HO} \bullet)$ normally produced by ETC complex I and III are scavenged by endogenous antioxidants [70], such as superoxide dismutase (SOD), catalase, reduced glutathione (GSH), and glutathione peroxidase (GPx). In patients with $\mathrm{AD}, \mathrm{COX}$ is inhibited and complex III is either left intact or stimulated resulting in increased levels of ROS [71]. Meanwhile, levels of SOD, GPx, and GSH are decreased in AD, which reduces the anti-oxidative power [72, 73] and aggravates the accumulation of ROS [71], resulting in cellular redox imbalance [74-76].

In addition, mitochondrial-related oxidative stress can be exacerbated by the intramitochondrial $A \beta$ accumulation, $\mathrm{A} \beta$-binding alcohol dehydrogenase $[25,77$, $78]$, and peroxidation of haem-A $\beta$ complexes under $\mathrm{H}_{2} \mathrm{O}_{2}$ $[79,80]$. The oxidative stress then triggers lipid peroxidation $[81,82]$ and protein oxidation $[74,83,84]$, which in turn, lead to oxidative dysfunction of key ETC complexes [85], and PDHC and KDGHC of the TCA cycle [86-88]. Oxidative stress also damages nuclear DNA (nDNA) [89-91] and mtDNA, leading to insufficient production of ETC complex subunits [89, 9193]. The combined effects of lipid peroxidation, protein oxidation and downregulated ETC subunits, lead to bioenergetic failure in $\mathrm{AD}$, which persists or worsens under oxidative stress.

An interesting mechanism relating to oxidative stress was reported to involve the peroxisome proliferator-activated receptor gamma coactivator 1-alpha (PGC-1 $\alpha$ ) and mitochondrial biogenesis. The PGC-1 $\alpha$, known as a central regulator of metabolism, induces the activities of respiratory complexes, which not only increase ROS production but at the same time increase the content of ROS detoxifying enzymes [94-97]. In cases of $\mathrm{AD}$, the PGC- $1 \alpha$ expression is reduced [98-101], implying lower levels of ROS-producing complexes I and III that possibly limit ROS levels in mitochondria. However, this phenomenon also lowers available ROS scavengers, exaggerating the accumulation of ROS. Some studies with ectopic expression have shown rescue of this phenotype in cells and animal models of $\mathrm{AD}[99,101$, 102], but some studies showed exacerbation of oxidative damage in mice models [103]. Collectively, this raises the question of the precise role of PGC- $1 \alpha$ downregulation in inducing oxidative stress in $\mathrm{AD}$. This requires further research to elucidate how and to what extent PGC- $1 \alpha$ downregulation mediates biogenesis (ROS production) and ROS detoxification contributing to oxidative damage 
in $\mathrm{AD}$ neuronal mitochondria, as well as which other intrinsic factors of mitochondria synergistically work with PGC- $1 \alpha$ to elicit the oxidative damage.

\subsection{Mitochondrial DNA damage}

Mitochondrial DNA, which encodes approximately $99 \%$ of polypeptide subunits of ETC complexes [85], has important roles in the vicious cycle of bioenergetic failure involving ETC defects and oxidative stress. Normally, chromatin changes occur in response to DNA damage from oxidative stress and ETC defects [104, 105]. However, mtDNA lacks protective histone and cannot be rescued by post-translational histone modification [93, 106]. As a result, mtDNA is prone to acquiring mutations at mitochondrial control regions such as T477C, T146C, and $\mathrm{T} 195 \mathrm{C}$ through mitoepigenetic changes due to its proximity to the ETC [107], leading to impaired assembly and activity of ETC proteins [108, 109]. These ETC impairments lead to mitochondrial energy defects and other pathological changes in $\mathrm{AD}$.

Indeed, mtDNA has a very high mutation rate that is about 10 fold faster than in nDNA, which accounts for the large number of non-specific changes [110, 111]. Mild non-specific damage in mtDNA mostly do not cause severe ETC impairments but coexists with normal mtDNA, which highlights the heteroplasmic state of mtDNA [111]. Deficits in energy production are limited if the proportion of mutant mtDNA remains low [111, 112], but as the proportion of mutant mtDNA increases within the neuron, energy production becomes impaired, leading to mitochondrial dysfunctions and contributing to late-onset sporadic AD [112].

\section{4. $\mathrm{Ca}^{2+}$ Dysregulation in mitochondria}

In post-mortem $\mathrm{AD}$ brains, mitochondrial $\mathrm{Ca}^{2+}$ homeostasis was found to be impaired due to changes in $\mathrm{Ca}^{2+}$ signalling [92, 113-115]. This dysfunction can be attributed to excess $\mathrm{Ca}^{2+}$ influx from extracellular fluid and $\mathrm{Ca}^{2+}$ efflux from the endoplasmic reticulum upon excitotoxicity. Excess $\mathrm{Ca}^{2+}$ in the cytosol enters the mitochondria via mPTP altering energy production [116]. In fact, mtDNA mutations and polymorphisms change the intracellular $\mathrm{Ca}^{2+}$ handling, leading to $\mathrm{Ca}^{2+}$ accumulation in mitochondria altering the mitochondrial matrix $\mathrm{pH}$. Excess cytosolic $\mathrm{Ca}^{2+}$ also activates apoptosis in a caspase-dependent manner [92, 117] and contributes to neuronal loss in AD. Furthermore, excess cytosolic $\mathrm{Ca}^{2+}$ due to $A \beta$ and P-tau dysregulates KIF5-Miro-Trakmediated mitochondrial transport to synapses [44]. The defects of mitochondrial dyanmics are discussed in the next section.

\subsection{Defective neuronal mitochondrial morphology and dynamics}

The morphology, dynamics, and motility of mitochondria have also been observed to be altered in AD. Multiple lines of evidence show that neuronal mitochondria in AD have fewer cristae and a paler matrix with enhanced fission and decreased fusion [108, 118-121]. Indeed, oxidative stress and $\mathrm{A} \beta$ in $\mathrm{AD}$ downregulated genes controlling mitochondrial fusion, such as inner membrane optic atrophy 1 , outer membrane mitofusin 1 and mitofusin 2, as well as upregulated fission genes, such as fission 1 and dynamin-related protein 1 [108, 119-121]. Additionally, mitochondrial axonal transport is impaired in $\mathrm{AD}$ leading to mitochondrial membrane depolarisation, facilitating retrograde movement of mitochondria [122] damaging synaptic viability [123-125].

\subsection{Disturbed mitophagy}

Healthy cytosolic organelles and proteins are maintained within cells through a clearing process called autophagy, which is initiated by autophagy-related proteins (Atg) [126], and occurs in either selective or non-selective manner [23]. In non-selective autophagy, a doublemembraned vesicle, known as autophagosome, engulfs the target along with other content in the cytoplasm to form an autolysosome, which degrades the content by lysosomal proteases [127]. In selective autophagy, nascent autophagosome cargo receptor proteins attach via poly-ubiquitin chains to specific targets for autophagy [128]. Specifically, damaged mitochondria are cleared from the cell by mitochondrial-selective autophagy or mitophagy [129]. Generally, initiation of the mitophagy pathway occurs via the relocation of cardiolipin, a diphosphatidylglycerol lipid, from the inner mitochondrial membrane to outer mitochondrial membrane [23]. Evidence has indicated that two proteins PTEN-induced putative kinase1 (PINK1) and parkin can also initiate the mitophagy pathway leading to autophagosome-mediated mitochondrial degradation [130]. In $A D$, high levels of $A \beta$ and P-Tau inhibit the expression of PINK1 and parkin, thereby reducing the number of autophagosomes leading to increased dysfunctional lysosomes and the severe disease pathology $[22,23]$.

3.6. Mitochondrial membrane permeabilisation and apoptosis

The unstable mitochondrial membrane acts as a modulator of mitochondrial-mediated apoptosis dependent and independent of caspase, and controls programmed cell death of neurones in AD. The MPTP on the surface of mitochondria are mediated by cyclophilin 
D [24]. When these pores open, cytochrome c (cyt c) is released from mitochondria into the cytosol, which activates caspases 9 and 3, and induces apoptosis [131133]. The increased opening of mPTP also disrupts complex V in the ETC, as discussed in section 3.1, in a mechanism involving excess cyclophilin D $[69,134]$. The opening of mPTP can be increased by the following factors: (1) oxidative stress; (2) $\mathrm{Ca}^{2+}$ accumulation in mitochondria; (3) A $\beta$ binding to voltage-dependent anion channels (VDAC) located on the mitochondrial outer membrane [123]; and (4) extracellular neurotrophic signals, such as neuronal growth factor (NGF) and its precursor, proNGF $[135,136]$.

In $\mathrm{AD}$ brains, there are lower levels of tropomyosin receptor kinase A (TrkA) [135, 136] and higher levels of proNGF [135-137] compared to normal controls. This indicates excess coupling of proNGF to its high-affinity P75 neurotrophin receptor (p75 ${ }^{\mathrm{NTR}}$ ) activating the C-Jun N-terminal kinase $(\mathrm{JNK}) / \mathrm{p} 53$ pathway [138-140]. This pathway further activates B-cell lymphoma-2 (Bcl-2)associated $\mathrm{X}$ protein (Bax), which increases $\mathrm{mPTP}$ opening and contributes to the apoptotic pathway.

\section{Cholinergic and Mitochondrial Dysfunction in AD}

Cholinergic transmission is performed by a specific group of neurones at the brainstem and basal forebrain and is involved in cognitive functioning, emotional reactions, memory formation, consolidation, and retrieval [141]. In $\mathrm{AD}$, there is insufficient cholinergic transmission, leading to memory and learning deficits. The decline in cholinergic transmission can result from (1) the loss of cholinergic neurones in the basal forebrain, hippocampus, and amygdala; (2) impairment of ACh metabolism due to imbalanced synthesis and breakdown; and (3) downregulation of ACh receptors (nAChR), except $\alpha 7$ subtype. How these changes are triggered and driven by mitochondrial dysfunctions is discussed in the section below.

\subsection{Mitochondrial membrane permeabilisation and cholinergic neuronal loss}

Discovered in the 1980s, cholinergic neuronal loss in AD was found to be a major contributor to cognitive impairment [142-145]. In AD, there are decreased levels of choline acetyltransferase (ChAT) [146], acetylcholinesterase (AChE) [147], and vesicular acetylcholine transporter (VAChT) [148], which are responsible for producing, breaking down, and packing ACh into vesicles, respectively. Neuronal death is tightly correlated with excessive permeabilisation of the mitochondrial membrane, mPTP opening, and release of pro-apoptotic proteins such as cyt $\mathrm{c}$, which activate caspases 9 and 3 to initiate cell death [131-133]. The hyperpermeability of the mitochondrial membrane results in cholinergic neuronal death and leads to ACh insufficiency.

\subsection{Inhibition of PDHC in mitochondria and ACh synthesis}

The 'bioenergetic failure' of mitochondria also affects ACh synthesis. Cholinergic neurones synthesise ACh from acetyl coenzyme A (acetyl-CoA) and choline via ChAT in the presynaptic cytoplasm. Most cellular acetylCoA is produced in mitochondria from pyruvate in the TCA cycle by the action of PDHC. The majority of mitochondrial acetyl-CoA stays in the mitochondrial compartment and is converted to citrate for energy production [149]. The remaining mitochondrial acetylCoA enters the cytosol via temporary release through $\mathrm{Ca}^{2+}$-induced mPTP upon depolarisation [150], where ATP citrate lyase (ACL) converts the released citrate into acetyl-CoA for further synthesis $[150,151]$.

As mentioned above, the activity of PDHC is diminished in AD. Many studies have reported that presence of APP and A $\beta$ peptides cause deficiency in pyruvate utilisation, leading to insufficient mitochondrial and cytosolic acetyl-CoA production for Ach in the cerebral cortex and hippocampus [152-154]. Multiple mechanisms have been proposed to explain this phenomenon. The first mechanism is that accumulating mitochondrial $\mathrm{Ca}^{2+}$ activates pyruvate dehydrogenase kinase (PDHK) and inhibits PDHC [155-157]. Meanwhile, excess mitochondrial $\mathrm{Ca}^{2+}$ leads to increased mPTP opening, resulting in the release of acetyl-CoA from mitochondria and long-term shortage of ACh and ATP $[155,158]$. The second mechanism is that APP and $\mathrm{A} \beta$ peptides activate mitochondrial tau protein kinase I/glycogen synthase kinase-3 $\beta$ (TPKI/GSK-3 $\beta$ ) pathways $[152,159]$, leading to dysfunction of lipoic acid, a PDHC cofactor [156]. Therefore, the pathological characteristics of AD hinder the ability of PDHC to convert pyruvate into acetyl-CoA, lowering the efficiency of ACh synthesis.

\subsection{Mitochondrial-induced oxidative stress and ACh breakdown}

Dysfunctional mitochondria can alter the activity of $\mathrm{AChE}$ and expression of its gene $A C H E$ in the brain, which affects the degree of $\mathrm{ACh}$ breakdown. In vivo studies have shown that $\mathrm{A} \beta$-induced oxidative stress was associated with enhancements in AChE activity [160, 161]. Moreover, oxidative stress was also found to reduce AChE activity in zebrafish embryo by decreasing the expression of its gene, ache [162]. Interestingly, using an AChE inhibitor increased the activity of TCA enzymes and ETC complexes and decreased oxidative stress in $\mathrm{AD}$ 
patients and Tg mice [163, 164]. However, some studies have suggested that this effect might be due to another ligand on $\mathrm{AChE}$ inhibitor interacting with $\mathrm{A} \beta$ and $\alpha 7$ $\mathrm{nAChR}$ rather than through the direct inhibition of $\mathrm{AChE}$ [165-167]. Given the vague relationship between mitochondrial oxidative stress and the breakdown of ACh in $\mathrm{AD}$, the causality between the nuclear genome encoding AChE, AChE activity, and mitochondrial dysfunction in $\mathrm{AD}$ requires further clarification.

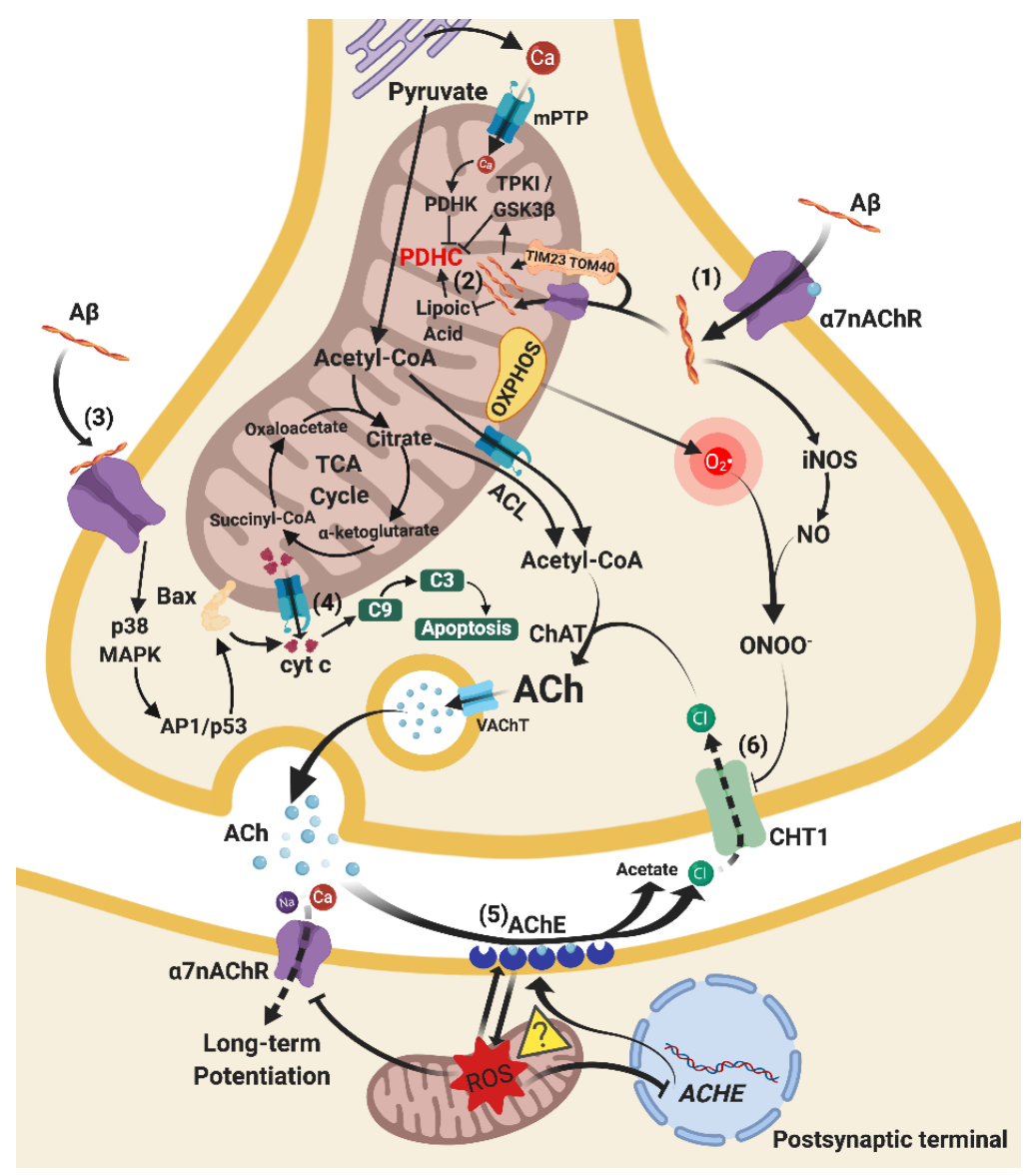

Figure 1. Relationships between mitochondrial and cholinergic dysfunctions. (1) Upregulated $\alpha 7$-nAChRs on cellular and mitochondrial membrane internalise $A \beta$ from the extracellular fluid to the cytosol and intramitochondrial matrix. The cytosolic $A \beta$ induces iNOS production. (2) PDHC is inhibited by $\mathrm{A} \beta$ via activation of TPK1/GSK3 $\beta$ and inhibition of lipoic acid and by excess $\mathrm{Ca}^{2+}$ influx via activation of PDHK, leading to decreased acetyl-CoA and subsequent ACh synthesis. (3) Upregulated cellular $\alpha$ 7-nAChRs combine with A $\beta$ to stimulate p38 MAPK and AP1/p53 signalling pathways. Bax proteins on the mitochondrial membrane are activated and enhance mPTP opening. (4) The mPTP opening on unstable mitochondrial membrane leads to release of cyt c, which activates caspase 9/3-dependent apoptosis. (5) AChE activity is enhanced by oxidative stress from mitochondrial dysfunction possibly through inhibition of CHAT nuclear gene. The enhanced AChE activity produces higher ROS levels which damage mitochondria, forming a vicious cycle of lowered ACh levels in the synapse (further investigations are needed). (6) CHT1 is inhibited due to ONOO' produced by $\mathrm{O}^{-} \bullet$ from mitochondria and NO from iNOS. Chloride ions reuptake decreases and reduces Ach synthesis. Arrows indicate stimulation, whereas a line with an end bar indicates inhibition. Dotted lines refer to inhibited pathways and question mark in a triangle ( 2 ) represents the need for future studies. Abbreviations: Acetyl-CoA, acetyl coenzyme A; ACh, acetylcholine; AChE, acetylcholinesterase; ACHE, gene that encodes acetylcholinesterase; ACL, ATP citrate lyase; AP-1/p53, activating protein-1 transcription factor / tumour protein $\mathrm{p} 53$; A $\beta$, amyloid-beta; Bax, Bcl-2-associated X protein; C3, caspase 3; C9, caspase 9; Ca, calcium ions; ChAT, choline acetyltransferase; CHT1, choline transporter 1; Cl, chlorine ions; cyt c, cytochrome c; iNOS, induced nitric oxide synthase; p38 MAPK, p38 mitogen-activated protein kinase signalling cascade; mPTP, mitochondrial permeability transition pore; Na, sodium ions; $\mathrm{NO}$, nitric oxide; $\mathrm{O} 2 \bullet$, superoxide radical; ONOO-, peroxynitrite; OXPHOS, oxidative phosphorylation; PDHC, pyruvate dehydrogenase complex; PDHK, pyruvate dehydrogenase kinase; ROS, reactive oxygen species; TCA cycle, tricarboxylic acid cycle; TIM23, translocase of the inner membrane 23; TOM40, translocase of outer mitochondrial membrane 40 homolog; TPKI/GSK3 $\beta$, tau protein kinase I / Glycogen synthase kinase-3 beta signalling cascade; VAChT, vesicular acetylcholine transporter; $\alpha 7 \mathrm{nAChR}$, alpha 7 nicotinic acetylcholine receptor.

\subsection{Oxidative stress, nitrosative stress, and choline recycling}

Mitochondrial-induced oxidative stress via nitrosylative stress hinders the recycling of choline from the synapse leading to ACh deficiency. In late stage AD, levels of presynaptic high-affinity choline transporter 1 (CHT1) were observed to be decreased in synaptosomes in the hippocampus and neocortex of humans $[168,169]$ and $\mathrm{Tg}$ animals $[170,171]$. Cuddy et al. demonstrated the 
internalisation of CHT1 in SH-SY5Y neuroblastoma cells after treatment with nitric oxide (NO) donor (3morpholinosydnonimine), leading to peroxynitrite $\left(\mathrm{ONOO}^{-}\right)$formation $[171,172]$. SH-SY5Y cells treated with APP were also observed to have internalisation of CHT1 [173, 174], suggesting a connection between APP and $\mathrm{ONOO}^{-}$in choline transport deficits. In fact, APP and its derivatives together with $\mathrm{A} \beta$ promoted the formation of inducible nitric oxide synthase (iNOS) leading to NO formation, whereas dysfunctional mitochondria produced excess $\mathrm{O}_{2}{ }^{-}$, which combined to form $\mathrm{ONOO}^{-}$causing cellular nitrosative stress. The peroxynitrite-degraded proteasomes, which enhance the internalisation of CHT1, eventually lead to decreased choline reuptake from synaptic clefts [172]. By enhancing nitrosative stress at axonal terminals, the dysfunctional mitochondria restrict the availability of cytosolic choline, another major element for $\mathrm{ACh}$ synthesis, resulting in cholinergic dysfunction.

\subsection{Upregulated $\alpha 7-n A C h R$ and mitochondrial dysfunction}

Normally, muscarinic $\mathrm{ACh}$ receptors and $\mathrm{nAChR}$ are present on pre- and postsynaptic terminals. Binding of ACh on postsynaptic $\alpha 7-n A C h R$ stimulates long-term potentiation and facilitates learning and memory formation [175, 176]. High cytosolic oxidative stress inactivates $\mathrm{nAChRs}$ and induces rundown of ACh-evoked currents and long-term depression of cholinergic transmission [177], which suggests the oxidative stress produced by postsynaptic mitochondria can alter cholinergic neurotransmission.

The significant upregulation of $\alpha 7-n A C h R$ at the nucleus basalis of Meynert in AD is possibly due to a compensatory effect from the blocking or disruption by $\mathrm{A} \beta$, which maintains the cholinergic transmission [178180]. The binding of $A \beta$ to $\alpha 7-n A c h R$ on the cell membrane stimulates p38MAPK and Bax/Bal pathways to enhance mitochondrial membrane permeabilisation, which increases cyt $\mathrm{c}$ release and mitochondrialdependent apoptosis [178]. On the other hand, agonistic cellular and mitochondrial $\alpha 7-\mathrm{nAchR}$ can attenuate the p38 MAPK cascade [178], thereby preventing the formation of VDAC and subsequent mPTP opening, as well as mitochondrial-induced apoptosis [181].

Besides its expression on the cell membrane, $\alpha 7$ $\mathrm{nAchR}$ also presents on the mitochondrial membrane in parietal cortical and hippocampal cholinergic neurones. The $\alpha 7-n A c h R$ internalise $\mathrm{A} \beta$ from the cytoplasm to the mitochondrial matrix $[182,183]$ mediated by p38 MAPK, ERK1/2, and low-density lipoprotein receptor-related protein (LRP1) signalling pathways [19, 178, 182-184]. The $A \beta$ accumulation in mitochondria leads to further mitochondrial dysfunctions such as oxidative stress and inhibition of TCA enzymes.

\section{Monoaminergic Dysfunction and Mitochondrial Dysfunction in AD}

Monoaminergic neurotransmission is a diverse network that consists of serotoninergic, dopaminergic, norepinephrinergic, and histaminergic systems. Mitochondrial dysfunctions are associated with monoaminergic inactivity through various mechanisms. In this section, we discuss the common interactions shared between all monoamines and examine specific changes that occur in each system associated with mitochondrial dysfunction in AD.

\subsection{Monoamine oxidase inhibits mitochondrial functioning}

Monoamine oxidases (MAOs), present on the outer mitochondrial membrane of all monoaminergic neurones, are enzymes that catalyze the breakdown of monoamine transmitters. These enzymes are separated into (1) type A (MAO-A), which is extensively expressed in catecholaminergic neurones and eliminate 5-HT, NE, and HA; and (2) type B (MAO-B), which cleave DA [185]. Abnormal MAO activity promotes the loss of monoamines and mitochondrial peroxidation in AD. The activity of hippocampal MAO was significantly increased in humans carrying $\varepsilon 4$ allele of apolipoprotein $E$ and in experimental mouse models of AD [186-188]. This enhanced MAO activity not only causes insufficient monoamines for neurotransmission, but also induces significantly higher levels of peroxidative stress in monoaminergic neurones via $\mathrm{H}_{2} \mathrm{O}_{2}$ production. This peroxidative stress causes lipid peroxidation, protein oxidation, nDNA and mtDNA damage, and mitochondrial membrane instability, as well as inhibits the TCA cycle and ETC complexes. Thus, hyperactive MAOs in AD lead to monoaminergic deficiency and mitochondrial dysfunction at presynaptic terminals through peroxidative stress.

In addition, cytoplasmic $\mathrm{Ca}^{2+}$ levels affect MAO-A, which alters mitochondrial membrane stability. In a study of glial cell cultures with inhibited PI3K/Akt, ERK and p38 MAPK signalling pathway, free $\mathrm{Ca}^{2+}$ levels were increased resulting in enhanced MAO-A activity as part of the apoptotic pathway [189, 190]. The high cytosolic $\mathrm{Ca}^{2+}$ levels in AD lead to more $\mathrm{Ca}^{2+}$ binding to MAO-A, which increases MAO-A activity and affects mitochondrial membrane stability. Because $\mathrm{Ca}^{2+}$ homeostasis controls MAO-A, this also modulates mitochondrial permeabilisation and apoptosis. Indeed, artificially enhancing MAO-A by using a dopaminergic 
neurotoxin (NMRSal) increased the mitochondrial membrane potential and induced mPTP opening [191]. Therefore, MAO aggravates mitochondrial dysfunctions through a non-transcriptional pathway.

\subsection{Serotoninergic and mitochondrial dysfunction in $A D$}

Serotoninergic transmission is mediated through neurones located at the brainstem and basal forebrain [192]. Serotonin or 5-hydroxytryptamine (5-HT) is synthesised from tryptophan catalyzed by tryptophan hydrogenase (TPH) at presynaptic terminals and released into the synaptic cleft. Normally, 5-HT is broken down into 5hydroxyindoleacetic acid (5-HIAA) under the action of MAO-A. Mitochondrial dysfunction in AD leads to serotoninergic inefficiency via membrane permeabilisation and altered serotoninergic metabolism. Inadequate serotoninergic transmission causes ROS accumulation and further mitochondrial dysfunction, contributing to $\mathrm{AD}$ progression.

\subsubsection{Mitochondrial membrane permeabilisation and serotoninergic apoptosis}

Similar to the cholinergic system, mitochondrialmediated caspase-dependent apoptosis is one of the causes of serotoninergic neuronal loss. The loss of serotoninergic neurones ultimately decreases 5-HT neurotransmission. Studies in the past 20 years have revealed that patients with $\mathrm{AD}$ exhibit extensive loss of 5HT synthesising neurones in the dorsal and median raphe nuclei [193, 194], and this likely involves mitochondrial membrane permeabilisation and release of pro-apoptotic proteins such as cyt c.

\subsubsection{Mitochondrial dysfunction induces excessive 5-HT breakdown}

Mitochondrial dysfunctions in AD lead to 5-HT deficits through excessive 5-HT breakdown. In studies using platelets (which can mimic neurones with high APP metabolism and extensive storage of 5-HT) from $\mathrm{AD}$ patients and $\mathrm{Tg}$ mice, high peroxidative stress $(100 \mathrm{mM}$ $\mathrm{H}_{2} \mathrm{O}_{2}$ ) significantly decreased 5-HT secretion [195]. Indeed, $\mathrm{H}_{2} \mathrm{O}_{2}$ is produced from $\mathrm{O}_{2}{ }^{\bullet}$ formed in defective ETC in AD. In the cytoplasm of AD neurones, haem-A $\beta$ complex forms when haem is released from mitochondria [196]. Under high peroxidative stress, the haem-A $\beta$ complex breaks down 5-HT to dihydroxytryptamine or tryptamine-4,5-dione [79, 80, 197], which limits the neuroactivity of the serotoninergic system in AD.

\subsubsection{5-HT insufficiency induces mitochondrial dysfunction}

Inhibiting tryptophan hydroxylase (Tph) and gene knockout in mice to achieve 5-HT deficiency lowered levels of citrate, oxoglutarate, succinate, pyruvate, and antioxidants, which increased oxidative stress [198, 199]. Moreover, dysregulated lipid metabolism was observed in TPH knockout mice, implying that serotoninergic dysfunction might change the lipid composition and induce pathological and functional changes, as well as alter physical properties such as mitochondrial membrane thickness [199]. These results indicate that lower levels of 5-HT were associated with inhibited TCA enzymes and lowered energy production via oxidative stress, but the exact molecular mechanism remains obscure and requires further investigation.

\subsubsection{5-HT1A receptors and mitochondrial bioenergetic distribution}

The mitochondrial movement in the axons of rat hippocampus are greatly facilitated by the activation of 5HT1A receptors via stimulation of Akt and inhibition of GSK3 $\beta$ [200]. However, AD neurones have limited binding of 5-HT to 5-HT1A receptors due to downregulated receptors and increased breakdown of 5HT [201-203], resulting in defective axonal transport of mitochondria. Inadequate binding on 5-HT1A receptors leads to impaired redistribution of energy resources in presynaptic terminals. Therefore, cellular energy production might not meet requirements, compromising global energy distribution and leading to bioenergetic failure in serotoninergic neurones.

\subsubsection{Insufficient melatonin and mitochondrial dysfunction}

Melatonin possesses anti-oxidative and anti-inflammatory properties, which activates the Bcl-2 pathway to decrease mitochondrial membrane permeabilisation [204, 205], and scavenges ROS to restore cellular oxidative balance [206]. Deficiency of 5-HT in AD decreases the precursor for melatonin production leading to insufficient melatonin. A change in the concentration of melatonin increases MPTP opening, induces oxidative stress, and impairs energy production in neuronal mitochondria. Melatonin treatment was able to rescue the inhibition of ETC and subsequent decrease in ATP production in AD experimental models [207, 208]. 


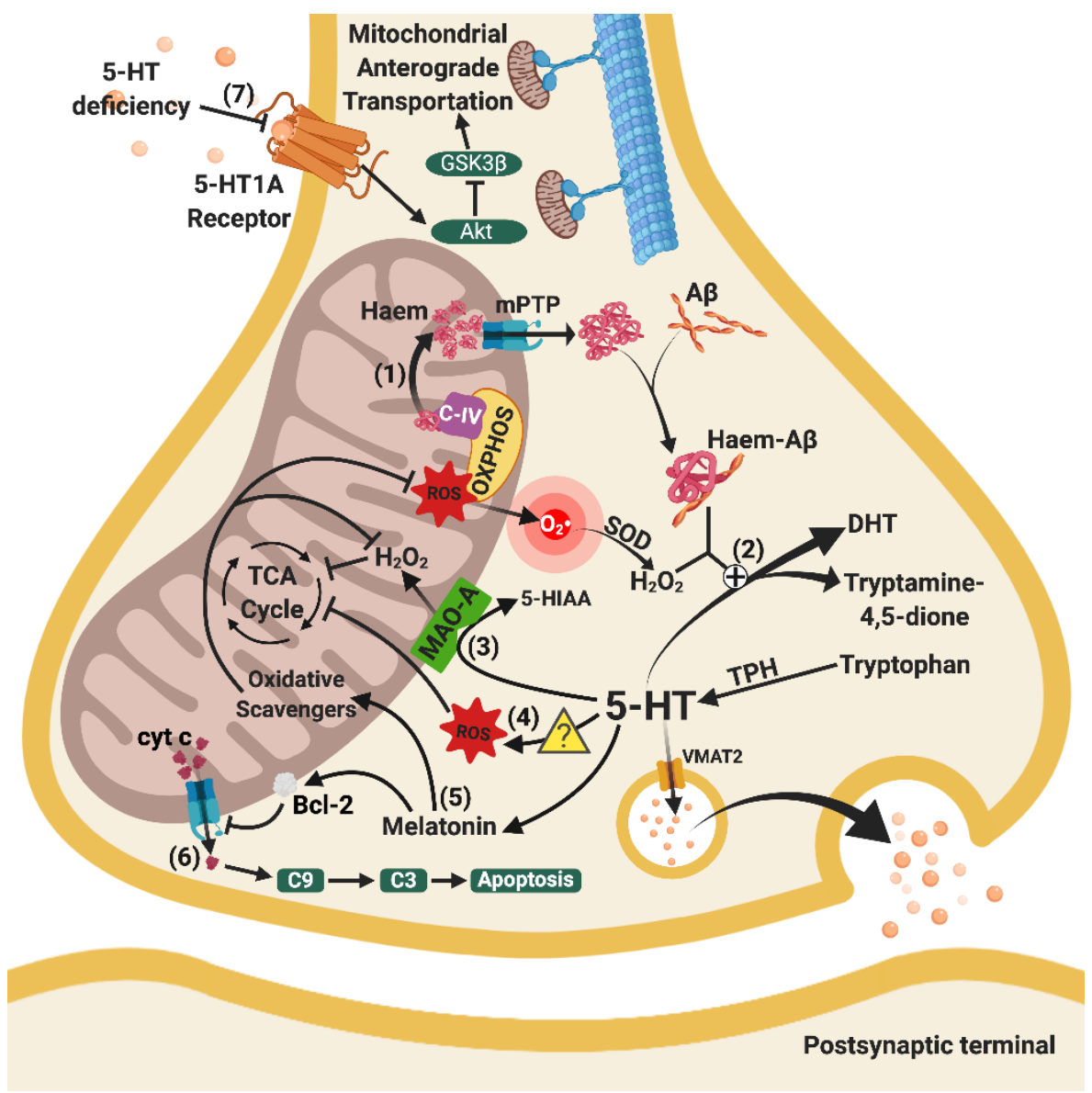

Figure 2. Relationships between mitochondrial and serotoninergic dysfunctions. (1) Haem from C-IV of OXPHOS released from mitochondria through increased mPTP opening bind with cytosol A $\beta$ to form haem-A $\beta$ complexes. (2) Mitochondrial dysfunction enhances the clearance of 5-HT through the combined effects of haem-A $\beta$ complexes and peroxide activity $\left(\mathrm{H}_{2} \mathrm{O}_{2}\right)$ from defective ETC. (3) Enhanced activity of MAO-A excessively breaks down 5-HT, leading to 5-HT-deficiency and $\mathrm{H}_{2} \mathrm{O}_{2}$, which lowers the efficiency of the TCA cycle. (4) 5-HT is associated with increased ROS levels (further research is needed to elucidate the precise molecular mechanisms), which damage enzymes in the TCA cycle. (5) Loss of 5-HT leads to the loss of anti-oxidative and anti-inflammatory melatonin, indirectly facilitating oxidative damage in mitochondria, reducing the activation of the Bcl-2 pathway. (6) Increased $\mathrm{mPTP}$ opening on the mitochondrial membrane leads to the release of cyt c, activating mitochondrial-mediated caspase-activated apoptosis. (7) Decreased 5-HT binding to 5HT-1A receptors hinders mitochondrial anterograde trafficking via inhibition of Akt and subsequent GSK3 $\beta$ stimulation, leading to altered normal energy distribution in the brain. Arrows indicate stimulation, whereas a line with an end bar indicates inhibition. A plus sign in circle $(\oplus)$ refers to catalysation and a question mark in triangle $(2)$ represents the need for future studies. Abbreviations: 5-HIAA, 5-Hydroxyindoleacetic acid; 5-HT, serotonin; 5-HT1A receptor, serotonin 1A receptor; Akt, protein kinase B; A $\beta$, amyloid-beta; Bcl-2, B-cell lymphoma 2; C-IV, complex IV in electron transport chain; C3, caspase 3; C9, caspase 9; cyt c, cytochrome c; DHT, 5,7-dihydroxytryptamine; GSK3 $\beta$, glycogen synthase kinase- 3 beta; $\mathrm{H}_{2} \mathrm{O}_{2}$, hydrogen peroxide; MAO-A, monoamine oxidase A; mPTP, mitochondrial permeability transition pore; O2 $\bullet$, superoxide radicals; OXPHOS, oxidative phosphorylation; ROS, reactive oxygen species; SOD, superoxide dismutase; TCA cycle, tricarboxylic acid cycle; TPH, tryptophan hydroxylase; VMAT2, vesicular monoamine transporter 2.

\subsection{Dopaminergic system and mitochondrial dysfunction in $A D$}

The dopaminergic system consists of a specific group of DA producing neurones, which innervate from the ventral tegmental area (VTA) in the midbrain to ventral striatum and prefrontal cortex, and from the substantia nigra pars compacta $(\mathrm{SNpc})$ to the caudate nucleus and putamen
[209]. In AD, there are lower levels of DA in the cingulate gyrus, amygdala, striatum, and raphe nuclei [210], which tightly correlated with the disease severity [211]. This reduction in DA was accompanied by loss of its precursor and metabolites, namely L-3,4-dihydroxyphenylalanine (L-DOPA) and 3,4-dihydroxyphenylacetic acid (DOPAC), respectively [210]. 


\subsubsection{Mitochondrial-dependent apoptosis in the dopaminergic System}

The current evidence shows that dopaminergic dysfunction is associated with mitochondrial-mediated apoptosis, specifically excessive mitochondrial membrane permeabilisation. For a long time, it was debated whether the dopaminergic system was involved in the pathogenesis of AD. Several lines of evidence showed that depletion of the VTA volume leads to reduced outflow of DA to the hippocampus and nucleus accumbens. This depletion leads to the deterioration of memory formation and locomotor activities in humans and $\mathrm{Tg}$ animals [39, 212-215]. A recent study revealed that selective apoptosis was involved only in the VTA, and not SNpc, hippocampus, neocortex, and locus ceruleus (LC) of $\mathrm{Tg}$ mice in the pre-plaque stage of $\mathrm{AD}$ [39]. Intriguingly, in Parkinson's disease, selective apoptosis was found in the SNpc due to $\mathrm{mPTP}$ opening and oxidative stress [216]. Given that mitochondrialmediated selective apoptosis is involved in dopaminergic neuronal loss in the SNpc in Parkinson's disease, it is highly possible that the apoptosis observed in the VTA in $\mathrm{AD}$ shares the same mechanism. Further studies are needed to verify the hypothesis of a pathological connection between mitochondrial-mediated release of pro-apoptotic proteins and dopaminergic neuronal loss in the VTA in AD.

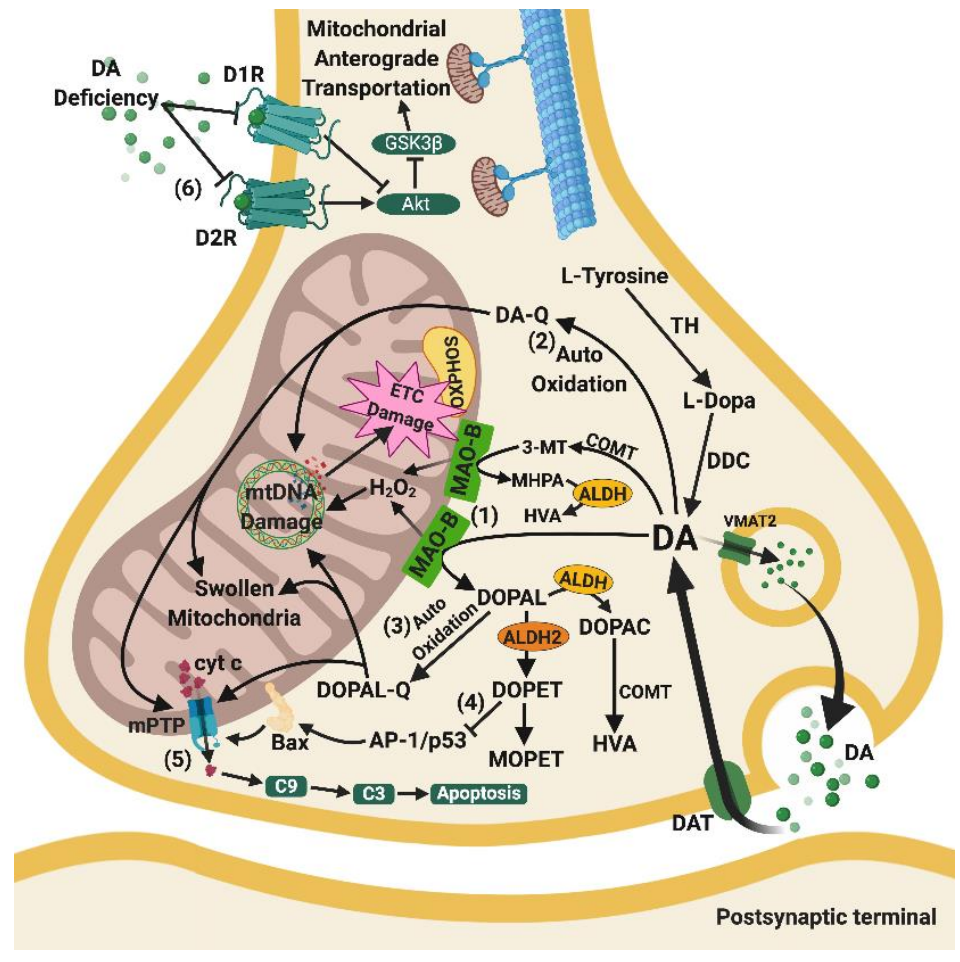

Figure 3. Relationships between mitochondrial and dopaminergic dysfunctions. (1) Overproduction of $\mathrm{H}_{2} \mathrm{O}_{2}$ from $\mathrm{MAO}-\mathrm{B}$ is considered a major peroxidative stressor that damages mtDNA and respiratory complexes of OXPHOS. (2) \& (3) DA and DOPAL are auto-oxidised to their respective quinones by ROS formed from OXPHOS. The quinones aggravate the oxidative stress resulting in swollen mitochondria and nuclear DNA damage, and subsequent deficits in OXPHOS complexes. (4) Loss of ALDH2 on mitochondrial surface in AD leads to lower levels of DOPET, which is an anti-apoptotic metabolite cleaved from DOPAL. Loss of DOPET compromises the inhibition of AP-1/P53 and subsequent Bax activation and mPTP opening. (5) DA deficiency also contributes to the inactivation of dopamine 1 and 2 receptors, which control the anterograde transportation of mitochondria. However, investigations are required to elucidate how this loss relates to mitochondrial distribution in the brain. Arrows indicate stimulation, whereas a line with an end bar indicates inhibition. Abbreviations: 3-MT, 3-methoxy-4-hydroxyphenethylamine; Akt, protein kinase $\mathrm{B}$; ALDH, aldehyde dehydrogenases; ALDH2, aldehyde dehydrogenase 2; AP-1/p53, activating protein-1 transcription factor / tumour protein p53; Bax, Bcl-2-associated X protein; C3, caspase3; C9, caspase 9; COMT, catechol-O-methyltransferase; cyt c, cytochrome c; D1R, dopamine 1 receptor; D2R, dopamine 2 receptor; DA, dopamine; DA-Q, dopamine quinone; DAT, dopamine transporter; DDC, DOPA decarboxylase; DOPA, dihydroxyphenylalanine; DOPAC, 3,4-dihydroxyphenylacetic acid; DOPAL, 3,4dihydroxyphenylacetaldehyde; DOPAL-Q, 3,4-dihydroxyphenylacetaldehyde quinone; DOPET, 3,4-dihydroxyphenylethylamine; ETC, electron transport chain; GSK3 $\beta$, glycogen synthase kinase-3 beta; $\mathrm{H}_{2} \mathrm{O}_{2}$, hydrogen peroxide; HVA, homovanillic acid; MAOB, monoamine oxidase B; MHPA, 3-methoxy-4-hydroxyphenylacetaldehyde; MOPET, 4-(2-hydroxyethyl)-2-methoxyphenol; mPTP, mitochondrial permeability transition pore; mtDNA, mitochondrial deoxyribonucleic acid; OXPHOS, oxidative phosphorylation; TH, tyrosine hydroxylase; VMAT2, vesicular monoamine transporter 2. 


\subsubsection{Contradictory action of DA metabolites and mitochondrial dysfunction}

Normally, DA is metabolised into several products including (1) 3-methoxytyramine by catechol-Omethyltransferase (COMT) that then converts to homovanillic acid (HVA) by MAO; (2) 3,4dihydroxyphenylacetaldehyde (DOPAL) by MAO that then mostly metabolises into DOPAC and HVA by aldehyde hydrogenase and COMT, respectively, and the rest converts to 3,4-dihydroxyphenyl ethanol (DOPET) via alcohol dehydrogenase; and (3) NE by DA betahydroxylase (DBH). Besides the loss of $\mathrm{DA}$ in $\mathrm{AD}$, there is also loss of its metabolite DOPAC. However, there is a higher concentration of DOPAC per neurone due to hyperactive and upregulated MAO [185]. DOPAC is neurotoxic due to its oxidative properties, which predisposes the mitochondrial structures to damage. In the early 1990s, DA and its metabolites were found to cause DNA damage and inhibit ETC [217]. Later, DA and DOPAC were found to undergo auto-oxidation in the high oxidative environment of mitochondria and MAO to form neurotoxic quinones [218]. Auto-oxidation of DA and DOPAC were found to be correlated with increased quinone content [219] and also its reductases [220] in early $\mathrm{AD}$. These quinones and their derivatives accumulate in the cytosol and add to the oxidative stress [221], leading to architectural changes in the mitochondria including $\mathrm{MPTP}$ opening and a swollen morphology [222]. When DA and its derivatives react with heavy metal ions, such as copper ions commonly seen in $\mathrm{AD}$, they non-enzymatically enhance the oxidative damage in DNA and mtDNA by up to 75 fold [223]. These processes aggravate the oxidative stress, damaging neuronal mitochondria in AD.

Surprisingly, DA and its derivatives also elicit neuroprotective effects on mitochondria. They reduce $A \beta$ accumulation and oxidative stress through the upregulation of haem-oxygenase 1 via oxidative transformation under aerobic conditions in microglia [224]. Moreover, another metabolite of DA, DOPET, was found to protect neuronal mitochondria in $A D$ by reversing $\mathrm{A} \beta$-induced mitochondrial-mediated caspasedependent apoptosis [225]. However, given only a small amount of DOPET is formed under physiological conditions, further evidence is needed. These contradictory effects of DA and its metabolites shed light on how DA and its metabolite levels influence mitochondrial functions in $\mathrm{AD}$.

\subsubsection{DA receptors and mitochondrial trafficking}

Unlike 5-HT, DA exhibits both stimulating and inhibiting effects on mitochondrial motility via a receptor-dependent mechanism, which affects universal brain energy distribution. Treatment with DA 2 receptor (D2R) agonists decreased mitochondrial transport via enhancing Akt, whereas treatment with DA 1 receptor (D1R) agonists promoted mitochondrial movement via inhibiting Akt [226]. Only the density of D1R was severely reduced in cerebral regions in AD [227], which suggests that inadequate binding on D1R hinders mitochondrial distribution in neurones. However, there are no in vivo studies addressing this hypothesis. Further studies are needed to confirm the degree of DA deficiency and subsequent downregulation of receptors in impairing mitochondrial trafficking in dopaminergic neurones in AD.

\subsection{Norepinephrinergic system and mitochondrial dysfunction in $A D$}

Norepinephrinergic transmission in the brain originates from the locus coeruleus (LC) in the upper dorsolateral pontine tegmentum and projects to the neocortex, hippocampus, thalamus, cerebellum, and spinal cord [209]. In AD, selective neuronal loss at the LC contributes to insufficient NE in hippocampal, temporal, cortical, and cerebellar regions $[154,228]$, as well as memory and cognitive impairments [40, 229]. The mitochondrial oxidative stress following neuronal activity-dependent $\mathrm{Ca}^{2+}$ influx was considered the major contributor to the vulnerability of LC apoptosis in early AD [40].

\subsubsection{The contradictory relationship between NE and mitochondrial dysfunction}

Under physiological conditions, NE protects neurones from oxidative damage by producing glutathione and peroxisome proliferator-activated receptor delta to enhance the antioxidant system [230, 231]. However, it is worth noting that the neuroprotective effect of NE only lasts a short time [232]. In addition, NE also rescues mitochondrial membrane depolarisation, caspase activation and apoptosis, and maintains the level of mitochondrial aggregation and fusion in $\mathrm{A} \beta$-toxified cells $[231,233]$. These additional effects of NE were produced by mediating $\beta$-adrenoreceptors, cAMP production, pCREB signalling and subsequent activation of NGF and BDNF pro-survival pathway [233]. The reduction of NE in the $\mathrm{LC}$ in $\mathrm{AD}$ alters mitochondrial functioning by decreasing oxidative scavengers, such as glutathione, increases oxidative stress, and promotes excessive mitochondrial membrane permeabilisation. The reduced $\mathrm{NE}$ was reported to cause excessive oxidative stress and decrease mitochondrial metabolism without activation of nuclear factor erythroid 2-related factor 2, $\beta$ - 
adrenoreceptors, and the downstream cAMP/PKA pathway [234].

Norepinephrinergic dysfunction in the cerebellum results in increased ROS production and possibly damage to mitochondrial functioning. In an $\mathrm{AD}$ experimental model overexpressing APP, cerebellar NE dysfunction was correlated with upregulation of NAPDH oxidases on the cell membrane [235]. The NADPH oxidases produced more ROS through stimulating $\mathrm{Ca}^{2+} /$ calmodulindependent protein kinases II (CaMKII) and PKC $\alpha$ [235]. The NADPH oxidase-induced CaMKII/PKC pathway activation then led to mtDNA damage and ETC activity through oxidative stress [236]. Although current studies have not reported the precise mechanisms of damage to mitochondria, it is possible that mitochondrial dysfunction might be caused by NE depletion due to loss of norepinephrinergic neurones at the LC.

On the other hand, high concentrations of NE were found to elevate cytosolic and mitochondrial ROS levels [237, 238], which were found to decrease mitochondrial transmembrane potential and energy metabolism in cell culture studies [238], and potentially enhances the neurotoxicity. Given that NE exhibits neuroprotective and neurotoxic effects according to the brain region, neuronal type, and NE concentration, in-depth studies are needed to investigate how NE insufficiency leads to mitochondrial dysfunction in $\mathrm{AD}$ according to the location, different stimuli, and NE levels.

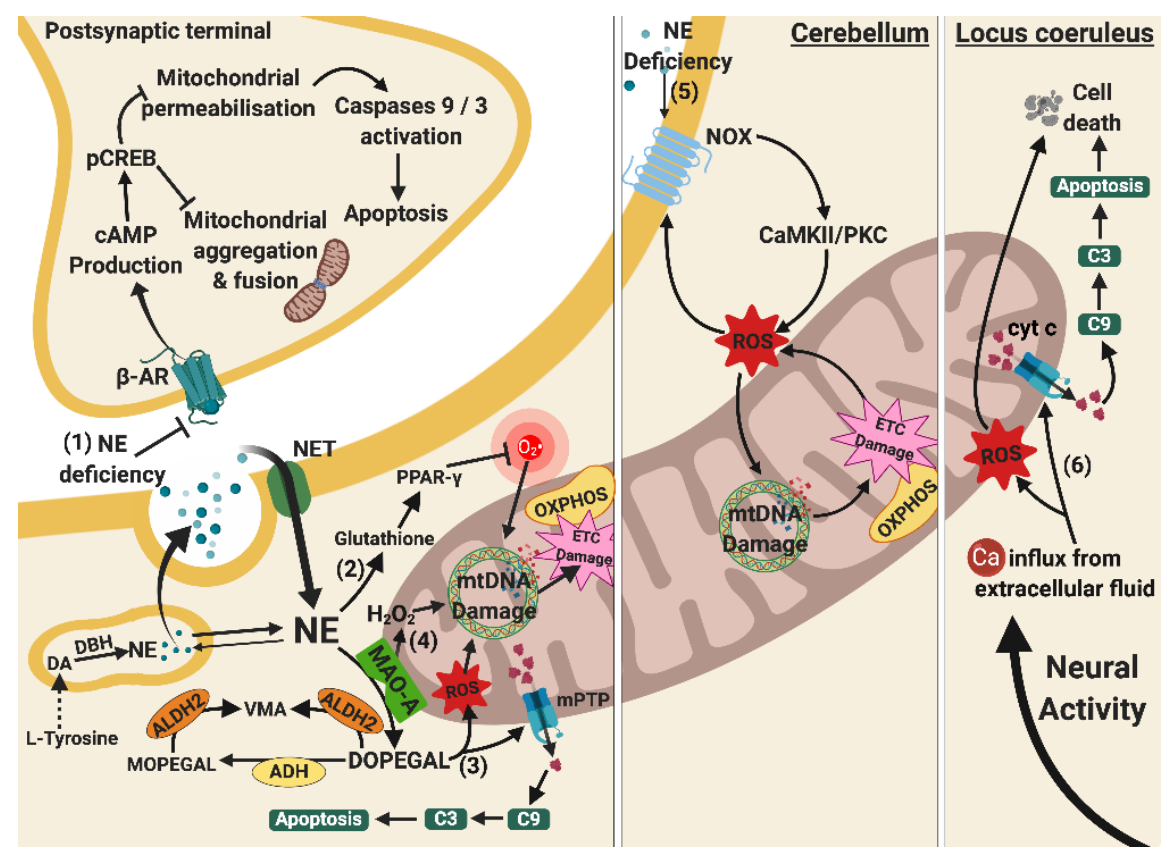

Figure 4. Relationships between mitochondrial and norepinephrine dysfunctions. (1) NE deficiency leads to loss of its protective effects on postsynaptic neurons. Normally, $\beta$-AR activation leads to cAMP and pCREB production, reducing mitochondrial aggregation, fission, and membrane permeabilisation. These prevent mitochondrial morphology changes and mitochondrial-mediated caspases-activated apoptosis. (2) NE deficiency at presynaptic terminals lowers the level of glutathione and PPAR- $\gamma$ activation, increasing O2 - via a receptor-independent pathway and predisposes to mtDNA damage. (3) DOPEGAL accumulates due to undermined ADH and ALDH2, generating both oxidative stress and mPTP opening. The mPTP opening facilitates release of pro-apoptotic cyt c and subsequent apoptosis. (4) Enhanced activity of MAO-A causes overproduction of $\mathrm{H}_{2} \mathrm{O}_{2}$ and along with oxidative stress from DOPEGAL stimulates mtDNA damage and ETC damage. (5) NE deficiency in cerebellum also causes mtDNA damage through the activation of NOX, CAMKII/PKC $\alpha$ signalling cascade, and ROS production. (6) Apoptosis of NE neurones at the locus coeruleus is associated with oxidative stress and mitochondrial-mediated caspases-dependent apoptosis due to $\mathrm{Ca}^{2+}$ influx upon neuronal activation, leading to reduced NE production. Arrows indicate stimulation, whereas a line with an end bar indicates inhibition. Dotted line represents a series of biochemical reactions. Abbreviations: ADH, alcohol dehydrogenase; ALDH 2, aldehyde dehydrogenase 2; C3, caspase3; C9, caspase 9; Ca, calcium ions; CAMKII/PKC, calmodulin-dependent protein kinase II/protein kinase C signalling cascade; cAMP, cyclic AMP; cyt c, cytochrome c; DA, dopamine; DBH, dopamine betahydroxylase; DOPEGAL, 3,4-dihydroxyphenylglycolaldehyde; ETC, electron transport chain; $\mathrm{H}_{2} \mathrm{O}_{2}$, hydrogen peroxide; MAO-A, monoamine oxidase A; MOPEGAL, 3-methoxy-4-hydroxyphenylglycolaldehyde; mPTP, mitochondrial permeability transitional pores; mtDNA, mitochondrial deoxyribonucleic acid; NE, norepinephrine; NET, norepinephrine transporter; NOX, NADPH oxidase; O2•-, superoxide radicals; OXPHOS, oxidative phosphorylation; pCREB, phosphorylated cyclic AMP response element binding; PPAR- $\gamma$, peroxisome proliferator-activated receptor gamma; ROS, reactive oxygen species; VMA, vanillylmandelic acid; $\beta$-AR, beta-2 adrenergic receptor. 


\subsubsection{Toxic NE metabolites induce mitochondrial dysfunction}

Following DA synthesis, DA is converted into NE in synaptic vesicles via DA beta-hydroxylase (DBH). The majority of NE diffuses out of the vesicles and enters the cytosol for other cellular functions. Cytosolic NE is broken down to 3,4-dihydroxyphenylglycolaldehyde (DOPEGAL) by MAO-A, and further broken down to vanillylmandelic acid (VMA) via aldehyde dehydrogenase 2 (ALDH2) on the outer mitochondrial membrane or by serial reactions of alcohol dehydrogenase $(\mathrm{ADH}), \mathrm{COMT}$ and ALDH2.

In $\mathrm{AD}$, the activity of MAO-A is enhanced and cleaves more NE into DOPEGAL [239], which is a neurotoxic metabolite that induces various mitochondrial dysfunctions, such as inducing oxidative stress [240, 241] and causing $\mathrm{Ca}^{2+}$-induced mPTP opening and apoptosis [239-241]. Ten-fold higher level of DOPEGAL is cytotoxic, causing mitochondrial dysfunction and ATP insufficiency in neurones [242]. In addition, DOPEGAL is formed in close proximity to the outer mitochondrial membrane and can have toxic effects on mitochondria before being broken down by ALDH2 or ADH [239]. In most cases, DOPEGAL accumulates intracellularly due to defective axonal transport at LC axonal terminals [239] and decreased levels of ALDH2 [243, 244]. Furthermore, ALDH2 deficiency in an experimental model of AD disabled the clearance of toxic aldehyde DOPEGAL, resulting in oxidative stress [245, 246] and cascadedependent apoptosis [246]. Overall, NE dysfunction results in accumulation of DOPEGAL, leading to oxidative damage of mitochondria and inducing excessive mitochondrial membrane permeability.

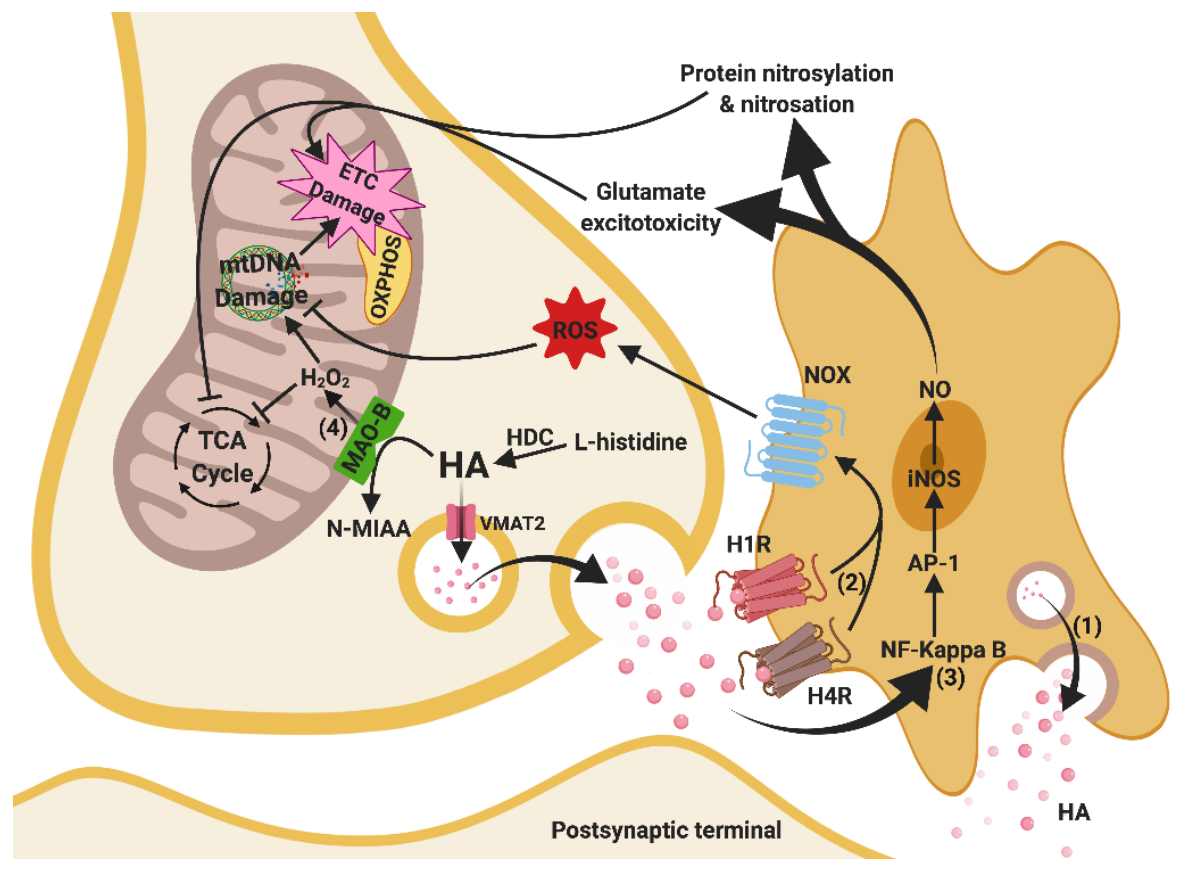

Figure 5. Relationships between mitochondrial and histaminergic dysfunctions. (1) Histamine content in the synaptic cleft increases due to microglial release. (2) Increased HA concentration stimulates H1R and H4R, and subsequent NADPH oxidase, which enhances ROS production and leads to mtDNA damage and ETC damage. (3) Increased HA content at the synapse also induces the NF kappa-B/AP-1 signalling pathway facilitating iNOS synthesis of NO, which in turn leads to glutamate excitotoxicity, nitrosylation and nitrosation of proteins, particularly in OXPHOS (ETC damage) and TCA cycle. (4) Excessive $\mathrm{H}_{2} \mathrm{O}_{2}$ produced from upregulated MAO-B leads to damage in mtDNA and the TCA cycle. These mechanisms ultimately damage mitochondrial bioenergy production in the brain. Arrows indicate stimulation, whereas a line with an end bar indicates inhibition. Abbreviations: AP-1, activating protein-1 transcription factor; ETC, electron transport chain; $\mathrm{H} 1 \mathrm{R}$, histaminergic 1 receptor; $\mathrm{H}_{2} \mathrm{O}_{2}$, hydrogen peroxide; $\mathrm{H} 4 \mathrm{R}$, histaminergic 4 receptor; HA, histamine; HDC, histidine decarboxylase; iNOS, induced nitric oxide synthase; MAO-B, monoamine oxidase B; mtDNA, mitochondrial deoxyribonucleic acid; N-MIAA, N-methyl indole acetic acid; NFkappaB, nuclear factor kappa-light-chain-enhancer of activated B cells; NO, nitric oxide; NOX, NADPH oxidase; OXPHOS, oxidative phosphorylation; ROS, reactive oxygen species; TCA cycle, tricarboxylic acid cycle; VMAT2, vesicular monoamine transporter 2. 


\subsection{Histaminergic system and mitochondrial dysfunction in $A D$}

The histaminergic system originates from the tuberomammillary nucleus (TMN) at the posterior hypothalamus and projects to diverse brain regions such as the neocortex, thalamus, basal ganglia, amygdala, and hippocampus [247]. Histamine levels in the brain are associated with cognition, attention, learning, memory, sensory, and motor functioning [248, 249]. Although histaminergic neurones in the TMN are known to be affected in the early stages of AD [250-252], the changes in HA levels have varied across studies. Some studies reported a reduction in HA levels in the hypothalamus, hippocampus, and temporal cortex of post-mortem $\mathrm{AD}$ brains [252-254], whereas one study reported elevated levels in the cortical and subcortical structures, except the globus pallidus and corpus callosum [247]. This discrepancy might be due to elevated HA production from microglia in the central nervous system [255]. Unlike cholinergic and other monoaminergic systems, to our knowledge, the relationship between the mitochondrialmediated apoptotic pathway and neuronal death in the TMN is still unclear.

\subsubsection{HA activates microglia-mediated mitochondrial dysfunction}

Histamine is an important inflammatory modulator that causes oxidative stress and mitochondrial dysfunction at pre- and postsynaptic terminals. It activates HA 1 and 4 receptors on microglial membranes to activate the NADPH oxidase signalling pathway and ROS production [256], leading to possible mtDNA damage. Moreover, HA also induces NO synthesis in microglia by upregulating iNOS via extracellular signalling to activate transcription factors like NF-KappaB and activator protein 1 [257]. The iNOS-induced NO can stimulate glutamate excitotoxicity and modify proteins by nitrosylation and nitrosation [258, 259]. Overall, HA induces ROS and NO in microglia that promotes oxidative stress and mitochondrial damage.

\section{Neuroinflammation, mitochondrial dysfunction, and neurotransmission failure}

Another important mechanism is that mitochondrial dysfunction mediates neuroinflammation, which possibly leads to synaptic deficits. An important source of neuroinflammation in neurodegenerative diseases is via mtDNA damage. Evidence indicates that mtDNA damage, which can be non-specific and specific, activates the canonical inflammatory pathway by stimulating both microglia and astrocytes [5, 260]. This eventually leads to increased expression of proinflammatory cytokines such as tumour necrosis factor- $\alpha$, interleukin (IL)-1 $\beta$, IL-6, and IL-10, as well as nuclear factor- $\mathrm{\kappa B}$ and toll-like receptors [261]. Stimulated microglia increase ROS and reactive nitrogen species levels, which subsequently activates glial inflammatory mechanisms [262]. The oxidative stress from mitochondrial dysfunction is potentiated by microglial-mediated oxidative stress, which pathologically induces oxidative damage in mtDNA, which again activates the above process [262]. Therefore, neuroinflammation likely occurs and is amplified due to mtDNA damage and oxidative stress, which are predominant in mitochondria in $\mathrm{AD}$.

Table 2. Common mitochondrial dysfunctions associated with neurotransmission in Alzheimer's disease.

\begin{tabular}{|r|c|c|c|c|c|}
\hline Mitochondrial dysfunctions & Acetylcholine & Serotonin & Dopamine & Norepinephrine & Histamine \\
\hline TCA cycle disturbance & ++ & + & N.A. & N.A. & + ? \\
\hline ETC impairment & $+?$ & + & + & + & $+?$ \\
\hline Oxidative stress & $+?$ & $+?$ & $+?$ & + & + \\
\hline mtDNA damage & N.A. & N.A. & + & + & $+?$ \\
\hline Ca $^{2+}$ dysregulation & + & N.A. & N.A. & + & + \\
\hline Morphological change & N.A. & N.A. & + & + & N.A. \\
\hline Transportation dysfunction & N.A. & + & $+?$ & N.A. & N.A. \\
\hline Membrane permeabilisation & ++ & + & $+?$ & ++ & $+?$ \\
\hline
\end{tabular}

The ' + ' indicates that the mitochondrial dysfunction is relevant and ' ++ ' indicates that the mitochondrial dysfunction is particularly relevant, with neurotransmission in Alzheimer's disease. A '?' indicates that the complete mechanism has not been clearly identified. Abbreviations: $\mathrm{Ca}^{2+}$, calcium ions; ETC, electron transport chain; N.A., not avaliable; mtDNA, mitochondrial deoxyribonucleic acid; TCA, tricarboxylic acid. 
Upon neuroinflammation, the axonal transport of mitochondria, especially retrograde trafficking, is disrupted [263]. This causes local energy depletion, which triggers impaired synaptic vesicle release and neurotransmission failure [44, 264], leading to cognitive deficits in AD. Overall, there is increasing evidence to support neurotransmitter deficits In $\mathrm{AD}$ due to mitochondrial dysregulation (oxidative stress and mtDNA damage) and induced neuroinflammation. However, so far there is no evidence of a system-specific association, which needs to be investigated.

\section{Conclusion and future perspectives}

Mitochondrial impairments in $\mathrm{AD}$ appear to occur upstream and downstream simultaneously. In fact, it appears that mitochondrial dysfunctions are connected to defective synaptic transmission and leads to changes in cholinergic and monoaminergic systems. Neurotransmission dysfunctions, such as 5-HT and DA deficit, also affect mitochondrial trafficking. All these pathological events act as a self-fuelling vicious cycle which ultimately leads to the disease progression in $\mathrm{AD}$ patients, culminating in clinical symptoms of memory deficit, depression, anxiety, and agitation. Table 2 summarizes the relationships reported in the literature and possible mechanisms that have not yet been proven or require further study.

Our current understanding not only sheds light on the pathological mechanisms, but also gives us clues for potential treatments that emphasise mitochondrial protection. In addition to biologics, drug and gene therapies, the major therapeutic approaches appear to be caloric restriction and exercise. Caloric restriction has been shown to reduce ROS and improve ATP/ROS ratio in mitochondria [265]. Exercise induces mitohormesis [266] and improves cognitive functions by promoting neurogenesis and synaptogenesis [267]. Available biologics such as engineered human mitochondrial transcription factor $\mathrm{A}$ has been shown to inhibit $\mathrm{A} \beta$ aggregation [268] and protect mtDNA function to improve cognitive function in animal models [269]. Drug therapies including mitochondrial-targeting bioenergetics (e.g., mitovitE, coenzyme Q10) can potentially rescue mitochondrial functions and improve $\mathrm{AD}$ conditions [270]. Recently, mtDNA functions in $\mathrm{AD}$ have been restored through gene therapy techniques called transcription activator-like effector nucleases and clustered regularly interspaced short palindromic repeats / associated protein 9 (CRISPR/Cas9) technology [110]. Although all of these approaches can improve mitochondrial dysfunction and AD pathology, none of them can completely rescue the condition.
A more accurate characterisation of the mechanisms underlying the complicated cross-talk between mitochondrial dysfunction and failure of cholinergic and monoaminergic systems could lead to a better understanding of how mitochondrial dysfunction affects the symptomology of $\mathrm{AD}$, which could advance our knowledge of the molecular mechanisms and facilitate neuroprotective strategies aimed at interrupting the mitochondrial cascade to successfully treat patients with $\mathrm{AD}$.

\section{Acknowledgements}

The scientific work was funded by grants from the Hong Kong Research Grant Council (RGC-ECS 27104616), and the University of Hong Kong URC Supplementary Funding (102009728) awarded to LWL.

\section{Declaration of Competing Interest}

None.

\section{References}

[1] Cerejeira J, Lagarto L, Mukaetova-Ladinska EB (2012). Behavioral and psychological symptoms of dementia. Front Neurol, 3:73.

[2] Alzheimer's Association (2018). 2018 Alzheimer's disease facts and figures. Alzheimer's \& Dementia, 14:367-429.

[3] Prince M, Bryce R, Albanese E, Wimo A, Ribeiro W, Ferri CP (2013). The global prevalence of dementia: A systematic review and metaanalysis. Alzheimer's \& Dementia, 9:63-75.e62.

[4] Hardy JA, Higgins GA (1992). Alzheimer's disease: the amyloid cascade hypothesis. Science, 256:184-185.

[5] Querfurth HW, LaFerla FM (2010). Alzheimer's disease. N Engl J Med, 362:329-344.

[6] Reddy PH, Manczak M, Mao P, Calkins MJ, Reddy AP, Shirendeb U (2010). Amyloid-beta and mitochondria in aging and Alzheimer's disease: implications for synaptic damage and cognitive decline. J Alzheimers Dis, 20 Suppl 2:S499-512.

[7] Reitz C, Mayeux R (2014). Alzheimer disease: Epidemiology, diagnostic criteria, risk factors and biomarkers. Biochemical Pharmacology, 88:640-651.

[8] Iqbal K, Liu F, Gong CX, Grundke-Iqbal I (2010). Tau in Alzheimer disease and related tauopathies. Current Alzheimer Research, 7:656-664.

[9] Šimić G, Babić Leko M, Wray S, Harrington C, Delalle I, Jovanov-Milošević N, et al. (2016). Tau protein hyperphosphorylation and aggregation in Alzheimer's disease and other tauopathies, and possible neuroprotective strategies. Biomolecules, 6:6. Livingston G, Sommerlad A, Orgeta V, Costafreda SG, Huntley J, Ames D, et al. (2017). Dementia prevention, intervention, and care. Lancet, 390:2673-2734. 
[11] Baumgart M, Snyder HM, Carrillo MC, Fazio S, Kim H, Johns H (2015). Summary of the evidence on modifiable risk factors for cognitive decline and dementia: A population-based perspective. Alzheimers Dement, 11:718-726.

[12] Ff Silva D, R Esteves A, R Oliveira C, M Cardoso S (2011). Mitochondria: the common upstream driver of amyloid- $\beta$ and tau pathology in Alzheimer's disease. Current Alzheimer Research, 8:563-572.

[13] Swerdlow RH, Khan SM (2004). A "mitochondrial cascade hypothesis" for sporadic Alzheimer's disease. Medical hypotheses, 63:8-20.

[14] Hirai K, Aliev G, Nunomura A, Fujioka H, Russell RL, Atwood CS, et al. (2001). Mitochondrial abnormalities in Alzheimer's disease. J Neurosci, 21:3017-3023.

[15] Beal MF, Hyman BT, Koroshetz W (1993). Do defects in mitochondrial energy metabolism underlie the pathology of neurodegenerative diseases? Trends in neurosciences, 16:125-131.

[16] Oliver DMA, Reddy PH (2019). Molecular Basis of Alzheimer's Disease: Focus on Mitochondria. J Alzheimers Dis:1-22.

[17] Swerdlow RH (2018). Mitochondria and Mitochondrial Cascades in Alzheimer's Disease. J Alzheimers Dis, 62:1403-1416.

[18] Atamna H, Frey WH, 2nd (2007). Mechanisms of mitochondrial dysfunction and energy deficiency in Alzheimer's disease. Mitochondrion, 7:297-310.

[19] Caldeira GL, Ferreira IL, Rego AC (2013). Impaired transcription in Alzheimer's disease: key role in mitochondrial dysfunction and oxidative stress. J Alzheimers Dis, 34:115-131.

[20] Rhein V, Song X, Wiesner A, Ittner LM, Baysang G, Meier F, et al. (2009). Amyloid-beta and tau synergistically impair the oxidative phosphorylation system in triple transgenic Alzheimer's disease mice. Proc Natl Acad Sci U S A, 106:20057-20062.

[21] Spuch C, Ortolano S, Navarro C (2012). New insights in the amyloid-Beta interaction with mitochondria. J Aging Res, 2012:324968.

[22] Hu Y, Li XC, Wang ZH, Luo Y, Zhang X, Liu XP, et al. (2016). Tau accumulation impairs mitophagy via increasing mitochondrial membrane potential and reducing mitochondrial Parkin. Oncotarget, 7:1735617368.

[23] Reddy PH, Oliver D (2019). Amyloid beta and phosphorylated tau-induced defective autophagy and mitophagy in alzheimer's disease. Cells, 8:488.

[24] Du H, Yan SS (2010). Mitochondrial permeability transition pore in Alzheimer's disease: cyclophilin D and amyloid beta. Biochim Biophys Acta, 1802:198204.

[25] Yan SD, Stern DM (2005). Mitochondrial dysfunction and Alzheimer's disease: role of amyloid-beta peptide alcohol dehydrogenase (ABAD). Int J Exp Pathol, 86:161-171.

[26] Manczak M, Reddy PH (2012). Abnormal interaction between the mitochondrial fission protein Drp1 and hyperphosphorylated tau in Alzheimer's disease neurons: implications for mitochondrial dysfunction and neuronal damage. Human molecular genetics, 21:2538-2547.

[27] Selkoe DJ (2002). Alzheimer's disease is a synaptic failure. Science, 298:789-791.

[28] Fitzjohn SM, Morton RA, Kuenzi F, Rosahl TW, Shearman M, Lewis H, et al. (2001). Age-related impairment of synaptic transmission but normal longterm potentiation in transgenic mice that overexpress the human APP695SWE mutant form of amyloid precursor protein. Journal of Neuroscience, 21:46914698.

[29] Boncristiano S, Calhoun ME, Kelly PH, Pfeifer M, Bondolfi L, Stalder M, et al. (2002). Cholinergic changes in the APP23 transgenic mouse model of cerebral amyloidosis. J Neurosci, 22:3234-3243.

[30] Woolf NJ, Butcher LL (2011). Cholinergic systems mediate action from movement to higher consciousness. Behav Brain Res, 221:488-498.

[31] Baker-Nigh A, Vahedi S, Davis EG, Weintraub S, Bigio EH, Klein WL, et al. (2015). Neuronal amyloid$\beta$ accumulation within cholinergic basal forebrain in ageing and Alzheimer's disease. Brain, 138:17221737.

[32] Bracco L, Bessi V, Padiglioni S, Marini S, Pepeu G (2014). Do cholinesterase inhibitors act primarily on attention deficit? A naturalistic study in Alzheimer's disease patients. Journal of Alzheimer's Disease, 40:737-742.

[33] Trillo L, Das D, Hsieh W, Medina B, Moghadam S, Lin B, et al. (2013). Ascending monoaminergic systems alterations in Alzheimer's disease. Translating basic science into clinical care. Neuroscience \& Biobehavioral Reviews, 37:1363-1379.

[34] Gottfries C-G, Bartfai T, Carlsson A, Eckerkäs S, Svennerholm L (1986). Multiple biochemical deficits in both gray and white matter of Alzheimer brains. Progress in Neuro-Psychopharmacology and Biological Psychiatry, 10:405-413.

[35] Storga D, Vrecko K, Birkmayer J, Reibnegger G (1996). Monoaminergic neurotransmitters, their precursors and metabolites in brains of Alzheimer patients. Neuroscience letters, 203:29-32.

[36] Heii A, Yosuke I, Kenji K, Takashi M, Reiji I (1992). Neurotransmitter changes in early-and late-onset Alzheimer-type dementia. Progress in NeuroPsychopharmacology and Biological Psychiatry, 16:883-890.

[37] Xu Y, Yan J, Zhou P, Li J, Gao H, Xia Y, et al. (2012). Neurotransmitter receptors and cognitive dysfunction in Alzheimer's disease and Parkinson's disease. Prog Neurobiol, 97:1-13.

[38] Lanari A, Amenta F, Silvestrelli G, Tomassoni D, Parnetti L (2006). Neurotransmitter deficits in behavioural and psychological symptoms of Alzheimer's disease. Mech Ageing Dev, 127:158-165. Nobili A, Latagliata EC, Viscomi MT, Cavallucci V, Cutuli D, Giacovazzo G, et al. (2017). Dopamine neuronal loss contributes to memory and reward dysfunction in a model of Alzheimer's disease. Nature 
communications, 8:14727.

[40] Chalermpalanupap T, Kinkead B, Hu WT, Kummer MP, Hammerschmidt T, Heneka MT, et al. (2013). Targeting norepinephrine in mild cognitive impairment and Alzheimer's disease. Alzheimer's research \& therapy, 5:21.

[41] Naddafi F, Mirshafiey A (2013). The neglected role of histamine in Alzheimer's disease. Am J Alzheimers Dis Other Demen, 28:327-336.

[42] Supnet C, Bezprozvanny I (2010). Neuronal calcium signaling, mitochondrial dysfunction, and Alzheimer's disease. J Alzheimers Dis, 20 Suppl 2:S487-498.

[43] Du H, Guo L, Yan SS (2012). Synaptic mitochondrial pathology in Alzheimer's disease. Antioxid Redox Signal, 16:1467-1475.

[44] Cai Q, Tammineni P (2017). Mitochondrial Aspects of Synaptic Dysfunction in Alzheimer's Disease. Journal of Alzheimer's disease, 57:1087-1103.

[45] Guo L, Tian J, Du H (2017). Mitochondrial Dysfunction and Synaptic Transmission Failure in Alzheimer's Disease. J Alzheimers Dis, 57:1071-1086.

[46] Mink JW, Blumenschine RJ, Adams DB (1981). Ratio of central nervous system to body metabolism in vertebrates: its constancy and functional basis. Am J Physiol, 241:R203-212.

[47] Sokoloff L. 1960. The metabolism of the central nervous system in vivo. In Handbook of Physiology, Section I, Neurophysiology. J. Field, H.W. Magoun, and V.E. Hall, editors. Washington D.C.: American Physiological Society. 1843-1864.

[48] Ferris SH, de Leon MJ, Wolf AP, Farkas T, Christman DR, Reisberg B, et al. (1980). Positron emission tomography in the study of aging and senile dementia. Neurobiol Aging, 1:127-131.

[49] Alexander GE, Chen K, Pietrini P, Rapoport SI, Reiman EM (2002). Longitudinal PET Evaluation of Cerebral Metabolic Decline in Dementia: A Potential Outcome Measure in Alzheimer's Disease Treatment Studies. Am J Psychiatry, 159:738-745.

[50] Friedland RP, Budinger TF, Ganz E, Yano Y, Mathis CA, Koss B, et al. (1983). Regional cerebral metabolic alterations in dementia of the Alzheimer type: positron emission tomography with $[18 \mathrm{~F}]$ fluorodeoxyglucose. J Comput Assist Tomogr, 7:590-598.

[51] de Leon MJ, Ferris SH, George AE, Reisberg B, Christman DR, Kricheff, II, et al. (1983). Computed tomography and positron emission transaxial tomography evaluations of normal aging and Alzheimer's disease. J Cereb Blood Flow Metab, 3:391-394.

[52] Desgranges B, Baron JC, de la Sayette V, Petit-Taboue MC, Benali K, Landeau B, et al. (1998). The neural substrates of memory systems impairment in Alzheimer's disease. A PET study of resting brain glucose utilization. Brain, 121 ( Pt 4):611-631.

[53] Mosconi L, De Santi S, Li J, Tsui WH, Li Y, Boppana $\mathrm{M}$, et al. (2008). Hippocampal hypometabolism predicts cognitive decline from normal aging. Neurobiol Aging, 29:676-692.

[54] Sorbi S, Bird ED, Blass JP (1983). Decreased pyruvate dehydrogenase complex activity in Huntington and Alzheimer brain. Ann Neurol, 13:72-78.

[55] Gibson GE, Sheu KF, Blass JP, Baker A, Carlson KC, Harding B, et al. (1988). Reduced activities of thiamine-dependent enzymes in the brains and peripheral tissues of patients with Alzheimer's disease. Arch Neurol, 45:836-840.

[56] Butterworth RF, Besnard AM (1990). Thiaminedependent enzyme changes in temporal cortex of patients with Alzheimer's disease. Metab Brain Dis, 5:179-184.

[57] Gibson GE, Haroutunian V, Zhang H, Park LC, Shi Q, Lesser M, et al. (2000). Mitochondrial damage in Alzheimer's disease varies with apolipoprotein E genotype. Ann Neurol, 48:297-303.

Bubber P, Haroutunian V, Fisch G, Blass JP, Gibson GE (2005). Mitochondrial abnormalities in Alzheimer brain: mechanistic implications. Ann Neurol, 57:695703.

[59] Parker WD, Jr., Filley CM, Parks JK (1990). Cytochrome oxidase deficiency in Alzheimer's disease. Neurology, 40:1302-1303.

[60] Parker WD, Jr., Parks JK (1995). Cytochrome c oxidase in Alzheimer's disease brain: purification and characterization. Neurology, 45:482-486.

[61] Maurer I (2000). A selective defect of cytochrome c oxidase is present in brain of Alzheimer disease patients. Neurobiology of Aging, 21:455-462.

[62] Atamna H, Liu J, Ames BN (2001). Heme Deficiency Selectively Interrupts Assembly of Mitochondrial Complex IV in Human Fibroblasts. Journal of Biological Chemistry, 276:48410-48416.

[63] Chernova T, Nicotera P, Smith AG (2006). Heme deficiency is associated with senescence and causes suppression of N-methyl-D-aspartate receptor subunits expression in primary cortical neurons. Mol Pharmacol, 69:697-705.

[64] Atamna H, Newberry J, Erlitzki R, Schultz CS, Ames BN (2007). Biotin deficiency inhibits heme synthesis and impairs mitochondria in human lung fibroblasts. $\mathrm{J}$ Nutr, 137:25-30.

[65] Anandatheerthavarada HK, Biswas G, Robin M-A, Avadhani NG (2003). Mitochondrial targeting and a novel transmembrane arrest of Alzheimer's amyloid precursor protein impairs mitochondrial function in neuronal cells. The Journal of Cell Biology, 161:41-54. [66] Devi L, Prabhu BM, Galati DF, Avadhani NG, Anandatheerthavarada HK (2006). Accumulation of amyloid precursor protein in the mitochondrial import channels of human Alzheimer's disease brain is associated with mitochondrial dysfunction. J Neurosci, 26:9057-9068.

[67] Hansson Petersen CA, Alikhani N, Behbahani H, Wiehager B, Pavlov PF, Alafuzoff I, et al. (2008). The amyloid beta-peptide is imported into mitochondria via the TOM import machinery and localized to mitochondrial cristae. Proc Natl Acad Sci U S A, 105:13145-13150.

[68] David DC, Hauptmann S, Scherping I, Schuessel K, Keil U, Rizzu P, et al. (2005). Proteomic and 
functional analyses reveal a mitochondrial dysfunction in P301L tau transgenic mice. J Biol Chem, 280:23802-23814.

[69] Beck SJ, Guo L, Phensy A, Tian J, Wang L, Tandon N, et al. (2016). Deregulation of mitochondrial F1FOATP synthase via OSCP in Alzheimer's disease. Nat Commun, 7:11483.

[70] Murphy MP (2009). How mitochondria produce reactive oxygen species. Biochem J, 417:1-13.

[71] Sohal RS (1993). Aging, cytochrome oxidase activity, and hydrogen peroxide release by mitochondria. Free Radic Biol Med, 14:583-588.

[72] Badía M-C, Giraldo E, Dasí F, Alonso D, Lainez JM, Lloret A, et al. (2013). Reductive stress in young healthy individuals at risk of Alzheimer disease. Free Radical Biology and Medicine, 63:274-279.

[73] Buizza L, Cenini G, Lanni C, Ferrari-Toninelli G, Prandelli C, Govoni S, et al. (2012). Conformational altered p53 as an early marker of oxidative stress in Alzheimer's disease. PLoS One, 7:e29789.

[74] Smith MA, Perry G, Richey PL, Sayre LM, Anderson VE, Beal MF, et al. (1996). Oxidative damage in Alzheimer's. Nature, 382:120-121.

[75] Smith MA, Rottkamp CA, Nunomura A, Raina AK, Perry G (2000). Oxidative stress in Alzheimer's disease. Biochim Biophys Acta, 1502:139-144.

[76] Markesbery WR, Carney JM (2006). Oxidative Alterations in Alzheimer's Disease. Brain Pathology, 9:133-146.

[77] Yao J, Du H, Yan S, Fang F, Wang C, Lue LF, et al. (2011). Inhibition of amyloid-beta (Abeta) peptidebinding alcohol dehydrogenase-Abeta interaction reduces Abeta accumulation and improves mitochondrial function in a mouse model of Alzheimer's disease. J Neurosci, 31:2313-2320.

[78] Lustbader JW, Cirilli M, Lin C, Xu HW, Takuma K, Wang N, et al. (2004). ABAD directly links Abeta to mitochondrial toxicity in Alzheimer's disease. Science, 304:448-452.

[79] Atamna H, Boyle K (2006). Amyloid-beta peptide binds with heme to form a peroxidase: relationship to the cytopathologies of Alzheimer's disease. Proc Natl Acad Sci U S A, 103:3381-3386.

[80] Chiziane E, Telemann H, Krueger M, Adler J, Arnhold J, Alia A, et al. (2018). Free Heme and Amyloid-beta: A Fatal Liaison in Alzheimer's Disease. J Alzheimers Dis, 61:963-984.

[81] Sayre LM, Zelasko DA, Harris PL, Perry G, Salomon RG, Smith MA (1997). 4-Hydroxynonenal-derived advanced lipid peroxidation end products are increased in Alzheimer's disease. J Neurochem, 68:2092-2097.

[82] Montine KS, Reich E, Neely MD, Sidell KR, Olson SJ, Markesbery WR, et al. (1998). Distribution of reducible 4-hydroxynonenal adduct immunoreactivity in Alzheimer disease is associated with APOE genotype. J Neuropathol Exp Neurol, 57:415-425.

[83] Smith MA, Richey Harris PL, Sayre LM, Beckman JS, Perry G (1997). Widespread peroxynitrite-mediated damage in Alzheimer's disease. J Neurosci, 17:2653-
2657.

[84] Smith CD, Carney JM, Starke-Reed PE, Oliver CN, Stadtman ER, Floyd RA, et al. (1991). Excess brain protein oxidation and enzyme dysfunction in normal aging and in Alzheimer disease. Proc Natl Acad Sci U S A, 88:10540-10543.

[85] Taanman JW (1999). The mitochondrial genome: structure, transcription, translation and replication. Biochim Biophys Acta, 1410:103-123.

[86] Mastrogiacomo F, Bergeron C, Kish SJ (1993). Brain $\alpha$-Ketoglutarate Dehydrotenase Complex Activity in Alzheimer's Disease. Journal of neurochemistry, 61:2007-2014.

[87] Gibson GE, Blass JP, Beal MF, Bunik V (2005). The $\alpha$-ketoglutarate-dehydrogenase complex: A Mediator Between Mitochondria and Oxidative Stress in Neurodegeneration. Molecular neurobiology, 31:4363.

[88] Gibson GE, Zhang H, Sheu KF, Bogdanovich N, Lindsay JG, Lannfelt L, et al. (1998). Alphaketoglutarate dehydrogenase in Alzheimer brains bearing the APP670/671 mutation. Ann Neurol, 44:676-681.

[89] Wang J, Xiong S, Xie C, Markesbery WR, Lovell MA (2005). Increased oxidative damage in nuclear and mitochondrial DNA in Alzheimer's disease. J Neurochem, 93:953-962.

[90] Nunomura A, Perry G, Pappolla MA, Wade R, Hirai K, Chiba S, et al. (1999). RNA Oxidation Is a Prominent Feature of Vulnerable Neurons in Alzheimer's Disease. The Journal of Neuroscience, 19:1959-1964.

[91] Mecocci P, MacGarvey U, Beal MF (1994). Oxidative damage to mitochondrial DNA is increased in Alzheimer's disease. Annals of Neurology: Official Journal of the American Neurological Association and the Child Neurology Society, 36:747-751.

[92] Sheehan JP, Swerdlow RH, Miller SW, Davis RE, Parks JK, Parker WD, et al. (1997). Calcium homeostasis and reactive oxygen species production in cells transformed by mitochondria from individuals with sporadic Alzheimer's disease. J Neurosci, 17:4612-4622.

[93] Santos RX, Correia SC, Zhu X, Smith MA, Moreira PI, Castellani RJ, et al. (2013). Mitochondrial DNA oxidative damage and repair in aging and Alzheimer's disease. Antioxid Redox Signal, 18:2444-2457.

[94] Sweeney G, Song J (2016). The association between PGC-1 $\alpha$ and Alzheimer's disease. Anat Cell Biol, 49:16.

[95] St-Pierre J, Drori S, Uldry M, Silvaggi JM, Rhee J, Jager S, et al. (2006). Suppression of reactive oxygen species and neurodegeneration by the PGC-1 transcriptional coactivators. Cell, 127:397-408.

[96] Handschin C, Spiegelman BM (2006). Peroxisome proliferator-activated receptor gamma coactivator 1 coactivators, energy homeostasis, and metabolism. Endocr Rev, 27:728-735.

[97] Austin S, St-Pierre J (2012). PGC1alpha and mitochondrial metabolism--emerging concepts and relevance in ageing and neurodegenerative disorders. 
J Cell Sci, 125:4963-4971.

[98] Pedros I, Petrov D, Allgaier M, Sureda F, Barroso E, Beas-Zarate C, et al. (2014). Early alterations in energy metabolism in the hippocampus of APPswe/PS1dE9 mouse model of Alzheimer's disease. Biochim Biophys Acta, 1842:1556-1566.

[99] Sheng B, Wang X, Su B, Lee HG, Casadesus G, Perry $\mathrm{G}$, et al. (2012). Impaired mitochondrial biogenesis contributes to mitochondrial dysfunction in Alzheimer's disease. J Neurochem, 120:419-429.

[100] Gong B, Chen F, Pan Y, Arrieta-Cruz I, Yoshida Y, Haroutunian V, et al. (2010). SCFFbx2-E3-ligasemediated degradation of BACE1 attenuates Alzheimer's disease amyloidosis and improves synaptic function. Aging cell, 9:1018-1031.

[101] Qin W, Haroutunian V, Katsel P, Cardozo CP, Ho L, Buxbaum JD, et al. (2009). PGC-1 $\alpha$ expression decreases in the Alzheimer disease brain as a function of dementia. Archives of neurology, 66:352-361.

[102] Katsouri L, Lim YM, Blondrath K, Eleftheriadou I, Lombardero L, Birch AM, et al. (2016). PPARgammacoactivator-1alpha gene transfer reduces neuronal loss and amyloid-beta generation by reducing betasecretase in an Alzheimer's disease model. Proc Natl Acad Sci U S A, 113:12292-12297.

[103] Dumont M, Stack C, Elipenahli C, Jainuddin S, Launay N, Gerges M, et al. (2014). PGC-1alpha overexpression exacerbates beta-amyloid and tau deposition in a transgenic mouse model of Alzheimer's disease. FASEB J, 28:1745-1755.

[104] Ghosh SS, Swerdlow RH, Miller SW, Sheeman B, Parker WD, Jr., Davis RE (1999). Use of cytoplasmic hybrid cell lines for elucidating the role of mitochondrial dysfunction in Alzheimer's disease and Parkinson's disease. Ann N Y Acad Sci, 893:176-191.

[105] Porteous WK, James AM, Sheard PW, Porteous CM, Packer MA, Hyslop SJ, et al. (1998). Bioenergetic consequences of accumulating the common 4977-bp mitochondrial DNA deletion. Eur J Biochem, 257:192-201.

[106] Liu B, Yip R, Zhou Z (2012). Chromatin remodeling, DNA damage repair and aging. Curr Genomics, 13:533-547.

[107] Zhang H, Liu Y, Lao M, Ma Z, Yi X (2011). Puerarin protects Alzheimer's disease neuronal cybrids from oxidant-stress induced apoptosis by inhibiting prodeath signaling pathways. Exp Gerontol, 46:30-37.

[108] Silva DF, Selfridge JE, Lu J, E L, Roy N, Hutfles L, et al. (2013). Bioenergetic flux, mitochondrial mass and mitochondrial morphology dynamics in AD and MCI cybrid cell lines. Hum Mol Genet, 22:3931-3946.

[109] Coskun PE, Beal MF, Wallace DC (2004). Alzheimer's brains harbor somatic mtDNA control-region mutations that suppress mitochondrial transcription and replication. Proc Natl Acad Sci U S A, 101:1072610731.

[110] Onyango IG (2018). Modulation of mitochondrial bioenergetics as a therapeutic strategy in Alzheimer's disease. Neural regeneration research, 13:19.

[111] Stewart JB, Chinnery PF (2015). The dynamics of mitochondrial DNA heteroplasmy: implications for human health and disease. Nat Rev Genet, 16:530-542. [112] Schon EA, Przedborski S (2011). Mitochondria: the next (neurode)generation. Neuron, 70:1033-1053.

[113] Zenisek D, Matthews G (2000). The Role of Mitochondria in Presynaptic Calcium Handling at a Ribbon Synapse. Neuron, 25:229-237.

[114] Billups B, Forsythe ID (2002). Presynaptic Mitochondrial Calcium Sequestration Influences Transmission at Mammalian Central Synapses. The Journal of Neuroscience, 22:5840-5847.

[115] Csordas G, Thomas AP, Hajnoczky G (1999). Quasisynaptic calcium signal transmission between endoplasmic reticulum and mitochondria. EMBO J, 18:96-108.

[116] Wan B, LaNoue KF, Cheung JY, Scaduto RC, Jr. (1989). Regulation of citric acid cycle by calcium. J Biol Chem, 264:13430-13439.

[117] Kazuno AA, Munakata K, Nagai T, Shimozono S, Tanaka M, Yoneda M, et al. (2006). Identification of mitochondrial DNA polymorphisms that alter mitochondrial matrix $\mathrm{pH}$ and intracellular calcium dynamics. PLoS Genet, 2:e128.

[118] Baloyannis SJ (2006). Mitochondrial alterations in Alzheimer's disease. J Alzheimers Dis, 9:119-126.

[119] Pickett EK, Rose J, McCrory C, McKenzie CA, King D, Smith C, et al. (2018). Region-specific depletion of synaptic mitochondria in the brains of patients with Alzheimer's disease. Acta Neuropathol, 136:747-757.

[120] Trimmer PA, Swerdlow RH, Parks JK, Keeney P, Bennett JP, Jr., Miller SW, et al. (2000). Abnormal mitochondrial morphology in sporadic Parkinson's and Alzheimer's disease cybrid cell lines. Exp Neurol, 162:37-50.

[121] Wang YJ, Wu FY, Pan HM, Zheng WZ, Feng C, Wang YF, et al. (2016). Lost region in amyloid precursor protein (APP) through TALEN-mediated genome editing alters mitochondrial morphology. Scientific Reports, 6:22244.

[122] Miller KE, Sheetz MP (2004). Axonal mitochondrial transport and potential are correlated. J Cell Sci, 117:2791-2804.

[123] Calkins MJ, Manczak M, Mao P, Shirendeb U, Reddy PH (2011). Impaired mitochondrial biogenesis, defective axonal transport of mitochondria, abnormal mitochondrial dynamics and synaptic degeneration in a mouse model of Alzheimer's disease. Hum Mol Genet, 20:4515-4529.

[124] Guo L, Du H, Yan S, Wu X, McKhann GM, Chen JX, et al. (2013). Cyclophilin D deficiency rescues axonal mitochondrial transport in Alzheimer's neurons. PLoS One, 8:e54914.

[125] Yu Q, Fang D, Swerdlow RH, Yu H, Chen JX, Yan SS (2016). Antioxidants Rescue Mitochondrial Transport in Differentiated Alzheimer's Disease TransMitochondrial Cybrid Cells. J Alzheimers Dis, 54:679-690.

[126] Eiyama A, Kondo-Okamoto N, Okamoto K (2013). Mitochondrial degradation during starvation is selective and temporally distinct from bulk autophagy 
in yeast. FEBS letters, 587:1787-1792.

[127] Glick D, Barth S, Macleod KF (2010). Autophagy: cellular and molecular mechanisms. J Pathol, 221:312.

[128] Zaffagnini G, Martens S (2016). Mechanisms of Selective Autophagy. J Mol Biol, 428:1714-1724.

[129] Archer SL (2013). Mitochondrial dynamicsmitochondrial fission and fusion in human diseases. New England Journal of Medicine, 369:2236-2251.

[130] Kerr JS, Adriaanse BA, Greig NH, Mattson MP, Cader MZ, Bohr VA, et al. (2017). Mitophagy and Alzheimer's Disease: Cellular and Molecular Mechanisms. Trends Neurosci, 40:151-166.

[131] Khan SM, Cassarino DS, Abramova NN, Keeney PM, Borland MK, Trimmer PA, et al. (2000). Alzheimer's disease cybrids replicate ?-amyloid abnormalities through cell death pathways. Annals of Neurology, 48:148-155.

[132] Cardoso SM, Santana I, Swerdlow RH, Oliveira CR (2004). Mitochondria dysfunction of Alzheimer's disease cybrids enhances Abeta toxicity. J Neurochem, 89:1417-1426.

[133] Cassarino DS, Swerdlow RH, Parks JK, Parker WD, Jr., Bennett JP, Jr. (1998). Cyclosporin A increases resting mitochondrial membrane potential in SY5Y cells and reverses the depressed mitochondrial membrane potential of Alzheimer's disease cybrids. Biochem Biophys Res Commun, 248:168-173.

[134] Gauba E, Chen H, Guo L, Du H (2019). Cyclophilin D deficiency attenuates mitochondrial F1Fo ATP synthase dysfunction via OSCP in Alzheimer's disease. Neurobiol Dis, 121:138-147.

[135] Mufson EJ, He B, Nadeem M, Perez SE, Counts SE, Leurgans S, et al. (2012). Hippocampal proNGF signaling pathways and beta-amyloid levels in mild cognitive impairment and Alzheimer disease. J Neuropathol Exp Neurol, 71:1018-1029.

[136] Counts SE, Nadeem M, Wuu J, Ginsberg SD, Saragovi HU, Mufson EJ (2004). Reduction of cortical TrkA but not p75(NTR) protein in early-stage Alzheimer's disease. Ann Neurol, 56:520-531.

[137] Fahnestock M, Michalski B, Xu B, Coughlin MD (2001). The precursor pro-nerve growth factor is the predominant form of nerve growth factor in brain and is increased in Alzheimer's disease. Mol Cell Neurosci, 18:210-220.

[138] Ioannou MS, Fahnestock M (2017). ProNGF, but Not NGF, Switches from Neurotrophic to Apoptotic Activity in Response to Reductions in TrkA Receptor Levels. Int J Mol Sci, 18:599.

[139] Roux P (2002). Neurotrophin signaling through the p75 neurotrophin receptor. Progress in Neurobiology, 67:203-233.

[140] Mufson EJ, Wuu J, Counts SE, Nykjaer A (2010). Preservation of cortical sortilin protein levels in MCI and Alzheimer's disease. Neurosci Lett, 471:129-133.

[141] Mesulam MM (2013). Cholinergic circuitry of the human nucleus basalis and its fate in Alzheimer's disease. J Comp Neurol, 521:4124-4144.

[142] Davies P, Maloney AJ (1976). Selective loss of central cholinergic neurons in Alzheimer's disease. Lancet, 2:1403.

[143] Whitehouse PJ, Price DL, Clark AW, Coyle JT, DeLong MR (1981). Alzheimer disease: evidence for selective loss of cholinergic neurons in the nucleus basalis. Ann Neurol, 10:122-126.

[144] Whitehouse PJ, Price DL, Struble RG, Clark AW, Coyle JT, Delon MR (1982). Alzheimer's disease and senile dementia: loss of neurons in the basal forebrain. Science, 215:1237-1239.

[145] Emre M, Heckers S, Mash DC, Geula C, Mesulam MM (1993). Cholinergic innervation of the amygdaloid complex in the human brain and its alterations in old age and Alzheimer's disease. J Comp Neurol, 336:117-134.

[146] Perry EK, Perry RH, Tomlinson BE, Blessed G, Gibson PH (1980). Coenzyme a-acetylating enzymes in Alzheimer's disease: Possible cholinergic 'compartment' of pyruvate dehydrogenase. Neuroscience Letters, 18:105-110.

[147] Kuhl DE, Koeppe RA, Minoshima S, Snyder SE, Ficaro EP, Foster NL, et al. (1999). In vivo mapping of cerebral acetylcholinesterase activity in aging and Alzheimer's disease. Neurology, 52:691-699.

[148] Efange SM, Garland EM, Staley JK, Khare AB, Mash DC (1997). Vesicular acetylcholine transporter density and Alzheimer's disease. Neurobiol Aging, 18:407413.

[149] Szutowicz A, Bielarczyk H, Jankowska-Kulawy A, Pawelczyk T, Ronowska A (2013). Acetyl-CoA the key factor for survival or death of cholinergic neurons in course of neurodegenerative diseases. Neurochem Res, 38:1523-1542.

[150] Bielarczyk H, Szutowicz A (1989). Evidence for the regulatory function of synaptoplasmic acetyl-CoA in acetylcholine synthesis in nerve endings. Biochem J, 262:377-380

[151] Jope RS (1979). High affinity choline transport and acetylCoA production in brain and their roles in the regulation of acetylcholine synthesis. Brain Research Reviews, 1:313-344.

[152] Hoshi M, Takashima A, Noguchi K, Murayama M, Sato M, Kondo S, et al. (1996). Regulation of mitochondrial pyruvate dehydrogenase activity by tau protein kinase I/glycogen synthase kinase 3beta in brain. Proceedings of the National Academy of Sciences, 93:2719-2723.

[153] Choi SH, Park CH, Koo JW, Seo JH, Kim HS, Jeong SJ, et al. (2001). Memory impairment and cholinergic dysfunction by centrally administered Abeta and carboxyl-terminal fragment of Alzheimer's APP in mice. FASEB J, 15:1816-1818.

[154] Bielarczyk H, Jankowska-Kulawy A, Höfling C, Ronowska A, Gul-Hinc S, Roßner S, et al. (2015). A $\beta P P-T r a n s g e n i c ~ 2576$ Mice Mimic Cell TypeSpecific Aspects of Acetyl-CoA-Linked Metabolic Deficits in Alzheimer's Disease. Journal of Alzheimer's Disease, 48:1083-1094.

[155] Szutowicz A, Madziar B, Pawelczyk T, Tomaszewicz M, Bielarczyk H (2004). Effects of NGF on 
acetylcholine, acetyl-CoA metabolism, and viability of differentiated and non-differentiated cholinergic neuroblastoma cells. J Neurochem, 90:952-961.

[156] Szutowicz A, Bielarczyk H, Gul S, Ronowska A, Pawelczyk T, Jankowska-Kulawy A (2006). Phenotype-dependent susceptibility of cholinergic neuroblastoma cells to neurotoxic inputs. Metab Brain Dis, 21:149-161.

[157] Szutowicz A, Tomaszewicz M, Bielarczyk H, Jankowska A (1998). Putative significance of shifts in acetyl-CoA compartmentalization in nerve terminals for disturbances of cholinergic transmission in brain. Dev Neurosci, 20:485-492.

[158] Madziar B, Tomaszewicz M, Matecki A, Bielarczyk H, Szutowicz A (2003). Interactions between p75 and TrkA receptors in differentiation and vulnerability of SN56 cholinergic cells to beta-amyloid. Neurochem Res, 28:461-465.

[159] Hoshi M, Takashima A, Murayama M, Yasutake K, Yoshida N, Ishiguro K, et al. (1997). Nontoxic amyloid beta peptide 1-42 suppresses acetylcholine synthesis. Possible role in cholinergic dysfunction in Alzheimer's disease. J Biol Chem, 272:2038-2041.

[160] Melo JB, Agostinho P, Oliveira CR (2003). Involvement of oxidative stress in the enhancement of acetylcholinesterase activity induced by amyloid betapeptide. Neurosci Res, 45:117-127.

[161] Khan A, Vaibhav K, Javed H, Khan MM, Tabassum R, Ahmed ME, et al. (2012). Attenuation of Abetainduced neurotoxicity by thymoquinone via inhibition of mitochondrial dysfunction and oxidative stress. Mol Cell Biochem, 369:55-65.

[162] Rodriguez-Fuentes G, Rubio-Escalante FJ, NorenaBarroso E, Escalante-Herrera KS, Schlenk D (2015). Impacts of oxidative stress on acetylcholinesterase transcription, and activity in embryos of zebrafish (Danio rerio) following Chlorpyrifos exposure. Comp Biochem Physiol C Toxicol Pharmacol, 172-173:1925.

[163] Saxena G, Singh SP, Agrawal R, Nath C (2008). Effect of donepezil and tacrine on oxidative stress in intracerebral streptozotocin-induced model of dementia in mice. Eur J Pharmacol, 581:283-289.

[164] Casademont J, Miro O, Rodriguez-Santiago B, Viedma P, Blesa R, Cardellach F (2003). Cholinesterase inhibitor rivastigmine enhance the mitochondrial electron transport chain in lymphocytes of patients with Alzheimer's disease. J Neurol Sci, 206:23-26.

[165] Inestrosa NC, Alvarez A, Perez CA, Moreno RD, Vicente M, Linker C, et al. (1996). Acetylcholinesterase accelerates assembly of amyloid- $\beta$-peptides into Alzheimer's fibrils: possible role of the peripheral site of the enzyme. Neuron, 16:881-891.

[166] Hou LN, Xu JR, Zhao QN, Gao XL, Cui YY, Xu J, et al. (2014). A new motif in the N-terminal of acetylcholinesterase triggers amyloid-beta aggregation and deposition. CNS Neurosci Ther, 20:59-66.
[167] Cottingham MG, Hollinshead MS, Vaux DJT (2002). Amyloid fibril formation by a synthetic peptide from a region of human acetylcholinesterase that is homologous to the Alzheimer's amyloid- $\beta$ peptide. Biochemistry, 41:13539-13547.

[168] Rylett RJ, Ball MJ, Colhoun EH (1983). Evidence for high affinity choline transport in synaptosomes prepared from hippocampus and neocortex of patients with Alzheimer's disease. Brain Res, 289:169-175.

[169] Bissette G, Seidler FJ, Nemeroff CB, Slotkin TA (1996). High affinity choline transporter status in Alzheimer's disease tissue from rapid autopsy. Ann N Y Acad Sci, 777:197-204.

[170] Payette DJ, Xie J, Guo Q (2007). Reduction in CHT1mediated choline uptake in primary neurons from presenilin-1 M146V mutant knock-in mice. Brain Res, 1135:12-21.

[171] Bales KR, Tzavara ET, Wu S, Wade MR, Bymaster FP, Paul SM, et al. (2006). Cholinergic dysfunction in a mouse model of Alzheimer disease is reversed by an anti-A beta antibody. J Clin Invest, 116:825-832.

[172] Cuddy LK, Gordon AC, Black SA, Jaworski E, Ferguson SS, Rylett RJ (2012). Peroxynitrite donor SIN-1 alters high-affinity choline transporter activity by modifying its intracellular trafficking. J Neurosci, 32:5573-5584.

[173] Cuddy LK, Seah C, Pasternak SH, Rylett RJ (2015). Differential regulation of the high-affinity choline transporter by wild-type and Swedish mutant amyloid precursor protein. J Neurochem, 134:769-782.

[174] Cuddy LK, Seah C, Pasternak SH, Rylett RJ (2017). Amino-Terminal beta-Amyloid Antibody Blocks betaAmyloid-Mediated Inhibition of the High-Affinity Choline Transporter CHT. Front Mol Neurosci, 10:361 [175] Ma L, Turner D, Zhang J, Wang Q, Wang M, Shen J, et al. (2014). Deficits of synaptic functions in hippocampal slices prepared from aged mice null alpha7 nicotinic acetylcholine receptors. Neurosci Lett, 570:97-101

[176] Stoiljkovic M, Kelley C, Nagy D, Hurst R, Hajos M (2016). Activation of alpha7 nicotinic acetylcholine receptors facilitates long-term potentiation at the hippocampal-prefrontal cortex synapses in vivo. Eur Neuropsychopharmacol, 26:2018-2023.

[177] Campanucci VA, Krishnaswamy A, Cooper E (2008). Mitochondrial reactive oxygen species inactivate neuronal nicotinic acetylcholine receptors and induce long-term depression of fast nicotinic synaptic transmission. J Neurosci, 28:1733-1744.

[178] Ma KG, Lv J, Yang WN, Chang KW, Hu XD, Shi LL, et al. (2018). The $\mathrm{p} 38$ mitogen activated protein kinase regulates beta-amyloid protein internalization through the alpha7 nicotinic acetylcholine receptor in mouse brain. Brain Res Bull, 137:41-52.

[179] Söderman A, Mikkelsen JD, West MJ, Christensen DZ, Jensen MS (2011). Activation of nicotinic $\alpha 7$ acetylcholine receptor enhances long term potentation in wild type mice but not in APPswe/PS1 $\triangle \mathrm{E} 9$ mice. Neuroscience Letters, 487:325-329.

[180] Mufson EJ, Counts SE, Perez SE, Ginsberg SD (2008). 
Cholinergic system during the progression of Alzheimer's disease: therapeutic implications. Expert Rev Neurother, 8:1703-1718.

[181] Gergalova G, Lykhmus O, Kalashnyk O, Koval L, Chernyshov V, Kryukova E, et al. (2012). Mitochondria express alpha7 nicotinic acetylcholine receptors to regulate $\mathrm{Ca} 2+$ accumulation and cytochrome c release: study on isolated mitochondria. PLoS One, 7:e31361.

[182] Yang WN, Ma KG, Chen XL, Shi LL, Bu G, Hu XD, et al. (2014). Mitogen-activated protein kinase signaling pathways are involved in regulating alpha7 nicotinic acetylcholine receptor-mediated amyloidbeta uptake in SH-SY5Y cells. Neuroscience, 278:276-290.

[183] Yang WN, Ma KG, Qian YH, Zhang JS, Feng GF, Shi LL, et al. (2015). Mitogen-activated protein kinase signaling pathways promote low-density lipoprotein receptor-related protein 1-mediated internalization of beta-amyloid protein in primary cortical neurons. Int $\mathrm{J}$ Biochem Cell Biol, 64:252-264.

[184] Ma K-G, Lv J, Hu X-D, Shi L-L, Chang K-W, Chen $\mathrm{X}-\mathrm{L}$, et al. (2016). The $\mathrm{p} 38$ mitogen-activated protein kinase signaling pathway is involved in regulating low-density lipoprotein receptor-related protein 1mediated $\beta$-amyloid protein internalization in mouse brain. The International Journal of Biochemistry \& Cell Biology, 76:75-86.

[185] Greenawalt JW, Schnaitman C (1970). An appraisal of the use of monoamine oxidase as an enzyme marker for the outer membrane of rat liver mitochondria. $\mathrm{J}$ Cell Biol, 46:173-179.

[186] Arora R, Deshmukh R (2017). Embelin Attenuates Intracerebroventricular Streptozotocin-Induced Behavioral, Biochemical, and Neurochemical Abnormalities in Rats. Mol Neurobiol, 54:6670-6680.

[187] Quartey MO, Nyarko JNK, Pennington PR, Heistad RM, Klassen PC, Baker GB, et al. (2018). Alzheimer Disease and Selected Risk Factors Disrupt a Coregulation of Monoamine Oxidase-A/B in the Hippocampus, but Not in the Cortex. Front Neurosci, 12:419.

[188] Perez SE, Lazarov O, Koprich JB, Chen EY, Rodriguez-Menendez V, Lipton JW, et al. (2005). Nigrostriatal dysfunction in familial Alzheimer's disease-linked APPswe/PS1DeltaE9 transgenic mice. J Neurosci, 25:10220-10229.

[189] Cao X, Li XM, Mousseau DD (2009). Calcium alters monoamine oxidase-A parameters in human cerebellar and rat glial C6 cell extracts: possible influence by distinct signalling pathways. Life Sci, 85:262-268.

[190] Cao X, Wei Z, Gabriel GG, Li X, Mousseau DD (2007). Calcium-sensitive regulation of monoamine oxidase-A contributes to the production of peroxyradicals in hippocampal cultures: implications for Alzheimer disease-related pathology. BMC Neurosci, 8:73.

[191] Naoi M, Maruyama W, Akao Y, Yi H, Yamaoka Y. 2006. Involvement of type A monoamine oxidase in neurodegeneration: regulation of mitochondrial signaling leading to cell death or neuroprotection. In Oxidative Stress and Neuroprotection: Springer. 67-77. [192] Simic G, Babic Leko M, Wray S, Harrington CR, Delalle I, Jovanov-Milosevic N, et al. (2017). Monoaminergic neuropathology in Alzheimer's disease. Prog Neurobiol, 151:101-138.

[193] Lai MK, Tsang SW, Esiri MM, Francis PT, Wong PT, Chen CP (2011). Differential involvement of hippocampal serotonin1A receptors and re-uptake sites in non-cognitive behaviors of Alzheimer's disease. Psychopharmacology (Berl), 213:431-439.

[194] Yamamoto T, Hirano A (1985). Nucleus raphe dorsalis in Alzheimer's disease: neurofibrillary tangles and loss of large neurons. Ann Neurol, 17:573-577.

[195] Ehrlich D, Hochstrasser T, Humpel C (2012). Effects of oxidative stress on amyloid precursor protein processing in rat and human platelets. Platelets, 24:2636.

[196] Atamna H, Frey WH, 2nd, Ko N (2009). Human and rodent amyloid-beta peptides differentially bind heme: relevance to the human susceptibility to Alzheimer's disease. Arch Biochem Biophys, 487:59-65.

[197] Mukherjee S, Seal M, Dey SG (2014). Kinetics of serotonin oxidation by heme-Abeta relevant to Alzheimer's disease. J Biol Inorg Chem, 19:1355-1365.

[198] Weng R, Shen S, Tian Y, Burton C, Xu X, Liu Y, et al. (2015). Metabolomics Approach Reveals Integrated Metabolic Network Associated with Serotonin Deficiency. Sci Rep, 5:11864.

[199] Weng R, Shen S, Burton C, Yang L, Nie H, Tian Y, et al. (2016). Lipidomic profiling of tryptophan hydroxylase 2 knockout mice reveals novel lipid biomarkers associated with serotonin deficiency. Anal Bioanal Chem, 408:2963-2973.

[200] Chen S, Owens GC, Crossin KL, Edelman DB (2007). Serotonin stimulates mitochondrial transport in hippocampal neurons. Mol Cell Neurosci, 36:472-483.

[201] Vidal B, Sebti J, Verdurand M, Fieux S, Billard T, Streichenberger N, et al. (2016). Agonist and antagonist bind differently to 5-HT1A receptors during Alzheimer's disease: A post-mortem study with PET radiopharmaceuticals. Neuropharmacology, 109:88-95.

[202] Lai MK, Tsang SW, Francis PT, Esiri MM, Keene J, Hope T, et al. (2003). Reduced serotonin 5-HT1A receptor binding in the temporal cortex correlates with aggressive behavior in Alzheimer disease. Brain Res, 974:82-87.

[203] Kepe V, Barrio JR, Huang SC, Ercoli L, Siddarth P, Shoghi-Jadid K, et al. (2006). Serotonin 1A receptors in the living brain of Alzheimer's disease patients. Proc Natl Acad Sci U S A, 103:702-707.

[204] Andrabi SA, Sayeed I, Siemen D, Wolf G, Horn TF (2004). Direct inhibition of the mitochondrial permeability transition pore: a possible mechanism responsible for anti-apoptotic effects of melatonin. FASEB J, 18:869-871.

[205] Jou MJ (2011). Melatonin preserves the transient mitochondrial permeability transition for protection during mitochondrial $\mathrm{Ca}(2+)$ stress in astrocyte. J 
Pineal Res, 50:427-435.

[206] Cardinali DP, Pagano ES, Scacchi Bernasconi PA, Reynoso R, Scacchi P (2013). Melatonin and mitochondrial dysfunction in the central nervous system. Horm Behav, 63:322-330.

[207] Dragicevic N, Copes N, O'Neal-Moffitt G, Jin J, Buzzeo R, Mamcarz M, et al. (2011). Melatonin treatment restores mitochondrial function in Alzheimer's mice: a mitochondrial protective role of melatonin membrane receptor signaling. J Pineal Res, 51:75-86.

[208] Hardeland R (2017). Melatonin and the electron transport chain. Cell Mol Life Sci, 74:3883-3896.

[209] Russo SJ, Nestler EJ (2013). The brain reward circuitry in mood disorders. Nat Rev Neurosci, 14:609-625.

[210] Storga D, Vrecko K, Birkmayer JGD, Reibnegger G (1996). Monoaminergic neurotransmitters, their precursors and metabolites in brains of Alzheimer patients. Neuroscience Letters, 203:29-32.

[211] Pinessi L, Rainero I, De Gennaro T, Gentile S, Portaleone P, Bergamasco B (1987). Biogenic amines in cerebrospinal fluid and plasma of patients with dementia of Alzheimer type. Funct Neurol, 2:51-58.

[212] Guzman-Ramos K, Moreno-Castilla P, Castro-Cruz M, McGaugh JL, Martinez-Coria H, LaFerla FM, et al. (2012). Restoration of dopamine release deficits during object recognition memory acquisition attenuates cognitive impairment in a triple transgenic mice model of Alzheimer's disease. Learning \& Memory, 19:453-460.

[213] Ambree O, Richter H, Sachser N, Lewejohann L, Dere E, de Souza Silva MA, et al. (2009). Levodopa ameliorates learning and memory deficits in a murine model of Alzheimer's disease. Neurobiol Aging, 30:1192-1204.

[214] Moreno-Castilla P, Rodriguez-Duran LF, GuzmanRamos K, Barcenas-Femat A, Escobar ML, Bermudez-Rattoni F (2016). Dopaminergic neurotransmission dysfunction induced by amyloid- $\beta$ transforms cortical long-term potentiation into longterm depression and produces memory impairment. Neurobiology of aging, 41:187-199.

[215] Xiang PY, Janc O, Grochowska KM, Kreutz MR, Reymann KG (2016). Dopamine agonists rescue A $\beta$ induced LTP impairment by Src-family tyrosine kinases. Neurobiology of aging, 40:98-102.

[216] Xie A, Gao J, Xu L, Meng D (2014). Shared mechanisms of neurodegeneration in Alzheimer's disease and Parkinson's disease. Biomed Res Int, 2014:648740.

[217] Spencer JP, Jenner A, Aruoma OI, Evans PJ, Kaur H, Dexter DT, et al. (1994). Intense oxidative DNA damage promoted by L-dopa and its metabolites. Implications for neurodegenerative disease. FEBS Lett, 353:246-250.

[218] Dauer W, Przedborski S (2003). Parkinson's disease: mechanisms and models. Neuron, 39:889-909.

[219] Ibanez C, Simo C, Barupal DK, Fiehn O, Kivipelto M, Cedazo-Minguez A, et al. (2013). A new metabolomic workflow for early detection of Alzheimer's disease. J Chromatogr A, 1302:65-71.

[220] Raina AK, Templeton DJ, Deak JC, Perry G, Smith MA (1999). Quinone reductase (NQO1), a sensitive redox indicator, is increased in Alzheimer's disease. Redox Rep, 4:23-27.

[221] Santa-María I, Hernández F, Smith MA, Perry G, Avila J, Moreno FJ (2005). Neurotoxic dopamine quinone facilitates the assembly of tau into fibrillar polymers. Molecular and cellular biochemistry, 278:203-212.

[222] Berman SB, Hastings TG (1999). Dopamine oxidation alters mitochondrial respiration and induces permeability transition in brain mitochondria: implications for Parkinson's disease. J Neurochem, 73:1127-1137.

[223] Spencer WA, Jeyabalan J, Kichambre S, Gupta RC (2011). Oxidatively generated DNA damage after $\mathrm{Cu}$ (II) catalysis of dopamine and related catecholamine neurotransmitters and neurotoxins: Role of reactive oxygen species. Free Radic Biol Med, 50:139-147.

[224] Nam E, Derrick JS, Lee S, Kang J, Han J, Lee SJC, et al. (2018). Regulatory Activities of Dopamine and Its Derivatives towards Metal-Free and Metal-Induced Amyloid- $\beta$ Aggregation, Oxidative Stress, and Inflammation in Alzheimer's Disease. ACS chemical neuroscience.

[225] Arunsundar M, Shanmugarajan TS, Ravichandran V (2014). 3,4-Dihydroxyphenylethanol Attenuates Spatio-Cognitive Deficits in an Alzheimer's Disease Mouse Model: Modulation of the Molecular Signals in Neuronal Survival-Apoptotic Programs. Neurotoxicity Research, 27:143-155.

[226] Chen S, Owens GC, Edelman DB (2008). Dopamine inhibits mitochondrial motility in hippocampal neurons. PLoS One, 3:e2804.

[227] Kumar U, Patel SC (2007). Immunohistochemical localization of dopamine receptor subtypes (D1R-D5R) in Alzheimer's disease brain. Brain Res, 1131:187-196. [228] Bondareff W, Mountjoy CQ, Roth M, Rossor MN, Iversen LL, Reynolds GP, et al. (1987). Neuronal degeneration in locus ceruleus and cortical correlates of Alzheimer disease. Alzheimer Dis Assoc Disord, 1:256-262.

[229] Weinshenker D (2008). Functional Consequences of Locus Coeruleus Degeneration in Alzheimers Disease. Current Alzheimer Research, 5:342-345.

[230] Madrigal JL, Kalinin S, Richardson JC, Feinstein DL (2007). Neuroprotective actions of noradrenaline: effects on glutathione synthesis and activation of peroxisome proliferator activated receptor delta. J Neurochem, 103:2092-2101.

[231] Traver S, Salthun-Lassalle B, Marien M, Hirsch EC, Colpaert F, Michel PP (2005). The neurotransmitter noradrenaline rescues septal cholinergic neurons in culture from degeneration caused by low-level oxidative stress. Mol Pharmacol, 67:1882-1891.

[232] Jhang KA, Lee EO, Kim HS, Chong YH (2014). Norepinephrine provides short-term neuroprotection against Abeta1-42 by reducing oxidative stress 
independent of Nrf2 activation. Neurobiol Aging, 35:2465-2473.

[233] Counts SE, Mufson EJ (2010). Noradrenaline activation of neurotrophic pathways protects against neuronal amyloid toxicity. J Neurochem, 113:649-660.

[234] Hurko O, Boudonck K, Gonzales C, Hughes ZA, Jacobsen JS, Reinhart PH, et al. (2010). Ablation of the locus coeruleus increases oxidative stress in tg2576 transgenic but not wild-type mice. International Journal of Alzheimer's Disease, 2010.

[235] Russo R, Cattaneo F, Lippiello P, Cristiano C, Zurlo F, Castaldo M, et al. (2018). Motor coordination and synaptic plasticity deficits are associated with increased cerebellar activity of NADPH oxidase, CAMKII, and PKC at preplaque stage in the TgCRND8 mouse model of Alzheimer's disease. Neurobiology of Aging, 68:123-133.

[236] Dikalov S (2011). Cross talk between mitochondria and NADPH oxidases. Free Radic Biol Med, 51:12891301.

[237] Schraml E, Quan P, Stelzer I, Fuchs R, Skalicky M, Viidik A, et al. (2007). Norepinephrine treatment and aging lead to systemic and intracellular oxidative stress in rats. Exp Gerontol, 42:1072-1078.

[238] Fu W, Luo H, Parthasarathy S, Mattson MP (1998). Catecholamines potentiate amyloid beta-peptide neurotoxicity: involvement of oxidative stress, mitochondrial dysfunction, and perturbed calcium homeostasis. Neurobiol Dis, 5:229-243.

[239] Burke WJ, Li SW, Schmitt CA, Xia P, Chung HD, Gillespie KN (1999). Accumulation of 3,4dihydroxyphenylglycolaldehyde, the neurotoxic monoamine oxidase A metabolite of norepinephrine, in locus ceruleus cell bodies in Alzheimer's disease: mechanism of neuron death. Brain Res, 816:633-637.

[240] Burke WJ, Kristal BS, Yu BP, Li SW, Lin T-S (1998). Norepinephrine transmitter metabolite generates free radicals and activates mitochondrial permeability transition: a mechanism for DOPEGAL-induced apoptosis. Brain Research, 787:328-332.

[241] Burke WJ, Schmitt CA, Gillespie KN, Li SW (1996). Norepinephrine transmitter metabolite is a selective cell death messenger in differentiated rat pheochromocytoma cells. Brain Research, 722:232235.

[242] Burke WJ, Li SW, Zahm DS, Macarthur H, Kolo LL, Westfall TC, et al. (2001). Catecholamine monoamine oxidase a metabolite in adrenergic neurons is cytotoxic in vivo. Brain Research, 891:218-227.

[243] Kamino K, Nagasaka K, Imagawa M, Yamamoto H, Yoneda H, Ueki A, et al. (2000). Deficiency in mitochondrial aldehyde dehydrogenase increases the risk for late-onset Alzheimer's disease in the Japanese population. Biochem Biophys Res Commun, 273:192196.

[244] Wang B, Wang J, Zhou S, Tan S, He X, Yang Z, et al. (2008). The association of mitochondrial aldehyde dehydrogenase gene (ALDH2) polymorphism with susceptibility to late-onset Alzheimer's disease in Chinese. J Neurol Sci, 268:172-175.
[245] Ohsawa I, Nishimaki K, Yasuda C, Kamino K, Ohta S (2003). Deficiency in a mitochondrial aldehyde dehydrogenase increases vulnerability to oxidative stress in PC12 cells. J Neurochem, 84:1110-1117.

[246] D'Souza Y, Elharram A, Soon-Shiong R, Andrew RD, Bennett BM (2015). Characterization of Aldh2-/-mice as an age-related model of cognitive impairment and Alzheimer's disease. Molecular brain, 8:27.

[247] Cacabelos R, Yamatodani A, Niigawa H, Hariguchi S, Tada K, Nishimura T, et al. (1989). Brain histamine in Alzheimer's disease. Methods Find Exp Clin Pharmacol, 11:353-360.

[248] Kohler CA, da Silva WC, Benetti F, Bonini JS (2011). Histaminergic mechanisms for modulation of memory systems. Neural Plast, 2011:328602.

[249] Brown RE, Stevens DR, Haas HL (2001). The physiology of brain histamine. Prog Neurobiol, 63:637-672.

[250] Braak H, Braak E, Bohl J (1993). Staging of Alzheimer-related cortical destruction. Eur Neurol, 33:403-408.

[251] Nakamura S, Takemura M, Ohnishi K, Suenaga T, Nishimura M, Akiguchi I, et al. (1993). Loss of large neurons and occurrence of neurofibrillary tangles in the tuberomammillary nucleus of patients with Alzheimer's disease. Neurosci Lett, 151:196-199.

[252] Schneider C, Risser D, Kirchner L, Kitzmuller E, Cairns N, Prast H, et al. (1997). Similar deficits of central histaminergic system in patients with Down syndrome and Alzheimer disease. Neurosci Lett, 222:183-186.

[253] Panula P, Rinne J, Kuokkanen K, Eriksson KS, Sallmen T, Kalimo H, et al. (1997). Neuronal histamine deficit in Alzheimer's disease. Neuroscience, 82:993-997.

[254] Mazurkiewicz-Kwilecki IM, Nsonwah S (1989). Changes in the regional brain histamine and histidine levels in postmortem brains of Alzheimer patients. Can J Physiol Pharmacol, 67:75-78.

[255] Motawaj M, Peoc'h K, Callebert J, Arrang JM (2010). CSF levels of the histamine metabolite telemethylhistamine are only slightly decreased in Alzheimer's disease. J Alzheimers Dis, 22:861-871.

[256] Rocha SM, Saraiva T, Cristovao AC, Ferreira R, Santos T, Esteves M, et al. (2016). Histamine induces microglia activation and dopaminergic neuronal toxicity via $\mathrm{H} 1$ receptor activation. J Neuroinflammation, 13:137.

[257] Rocha SM, Pires J, Esteves M, Graca B, Bernardino L (2014). Histamine: a new immunomodulatory player in the neuron-glia crosstalk. Front Cell Neurosci, 8:120.

[258] Knott AB, Bossy-Wetzel E (2009). Nitric oxide in health and disease of the nervous system. Antioxid Redox Signal, 11:541-554.

[259] Choi DY, Liu M, Hunter RL, Cass WA, Pandya JD, Sullivan PG, et al. (2009). Striatal neuroinflammation promotes Parkinsonism in rats. PLoS One, 4:e5482.

[260] Reddy PH, Beal MF (2008). Amyloid beta, mitochondrial dysfunction and synaptic damage: 
implications for cognitive decline in aging and Alzheimer's disease. Trends Mol Med, 14:45-53.

[261] von Bernhardi R, Eugenin-von Bernhardi L, Eugenin $\mathrm{J}$ (2015). Microglial cell dysregulation in brain aging and neurodegeneration. Front Aging Neurosci, 7:124.

[262] Wang J, Song Y, Chen Z, Leng SX (2018). Connection between Systemic Inflammation and Neuroinflammation Underlies Neuroprotective Mechanism of Several Phytochemicals in Neurodegenerative Diseases. Oxidative medicine and cellular longevity, 2018.

[263] Errea O, Moreno B, Gonzalez-Franquesa A, GarciaRoves PM, Villoslada P (2015). The disruption of mitochondrial axonal transport is an early event in neuroinflammation. Journal of neuroinflammation, 12:152.

[264] Sheng ZH, Cai Q (2012). Mitochondrial transport in neurons: impact on synaptic homeostasis and neurodegeneration. Nat Rev Neurosci, 13:77-93.

[265] Onyango IG, Dennis J, Khan SM (2016). Mitochondrial Dysfunction in Alzheimer's Disease and the Rationale for Bioenergetics Based Therapies.
Aging Dis, 7:201-214.

[266] Radak Z, Suzuki K, Higuchi M, Balogh L, Boldogh I, Koltai E (2016). Physical exercise, reactive oxygen species and neuroprotection. Free Radic Biol Med, 98:187-196.

[267] Chen WW, Zhang X, Huang WJ (2016). Role of physical exercise in Alzheimer's disease. Biomed Rep, 4:403-407.

[268] Oka S, Leon J, Sakumi K, Ide T, Kang D, LaFerla FM, et al. (2016). Human mitochondrial transcriptional factor A breaks the mitochondria-mediated vicious cycle in Alzheimer's disease. Sci Rep, 6:37889.

[269] Thomas RR, Khan SM, Smigrodzki RM, Onyango IG, Dennis J, Khan OM, et al. (2012). RhTFAM treatment stimulates mitochondrial oxidative metabolism and improves memory in aged mice. Aging (Albany NY), 4:620.

[270] Kumar A, Singh A (2015). A review on mitochondrial restorative mechanism of antioxidants in Alzheimer's disease and other neurological conditions. Front Pharmacol, 6:206. 